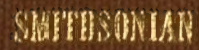

HBRABLE 



\section{(i)
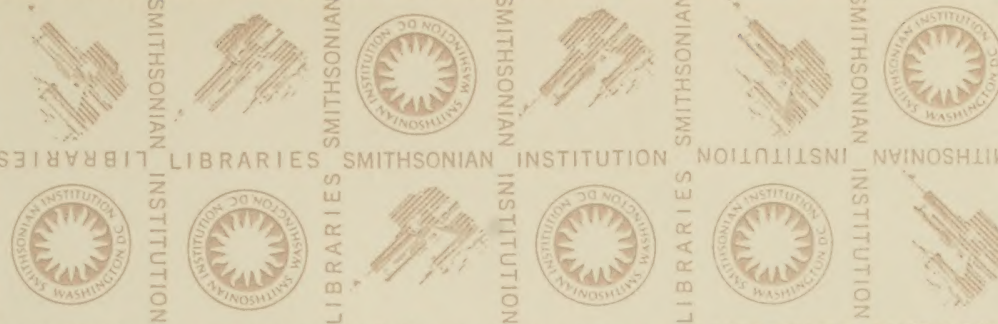 \\ g \\ (3) \\ (3)

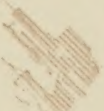 \\ (n) \\ E \\ (a) \\ (월 (2)

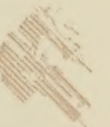 \\ (w) \\ (3) \\ E
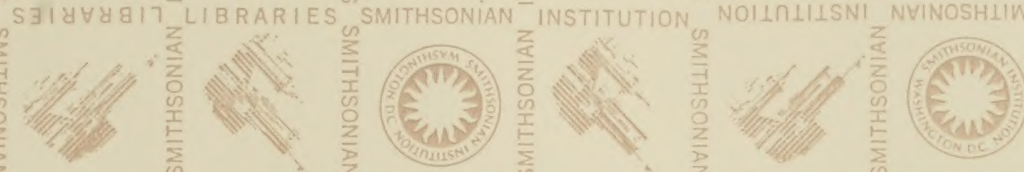 \\ (n)

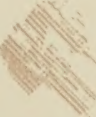 \\ (O) \\ (3) \\ (n) \\ $e_{2 \pi}^{\pi}$

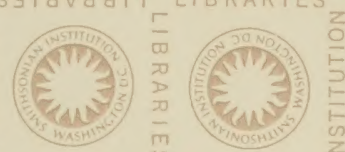

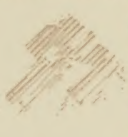 \\ (6) \\ (3) \\ M \\ (3) \\ Eviा
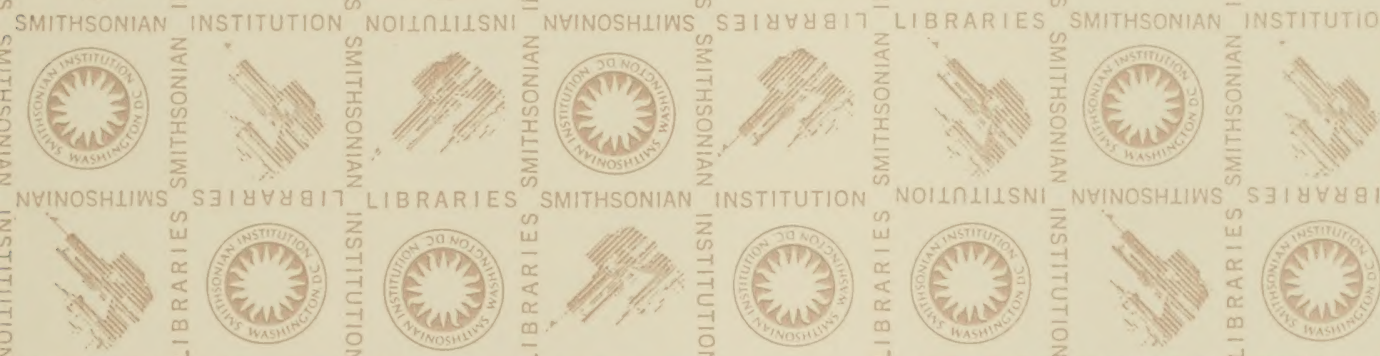 \\ (in)

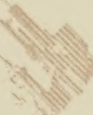 \\ (and) \\ हाiा
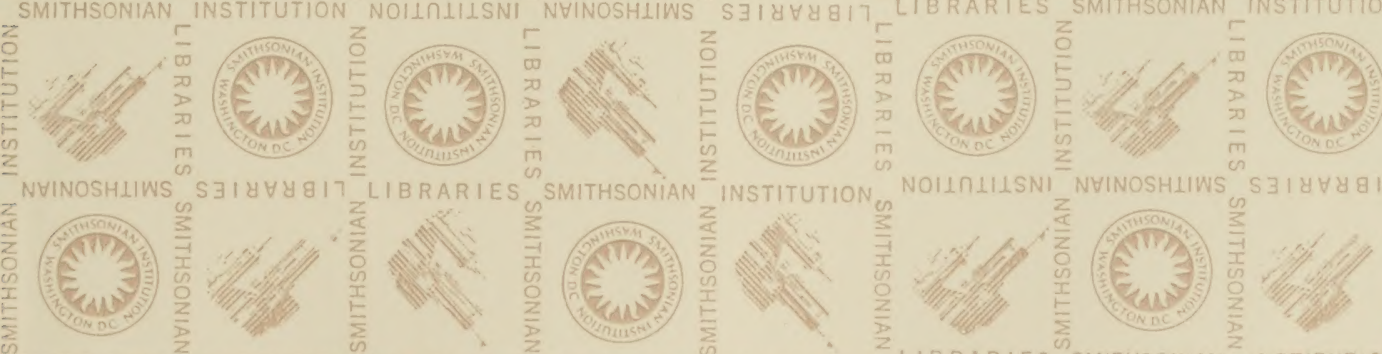

$$
\text { (2) } 10.10
$$ \\ NYINOSHLWWS

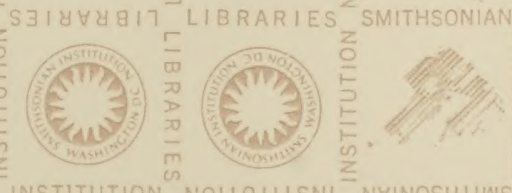

$$
\text { (iv) }
$$ \\ हैe}

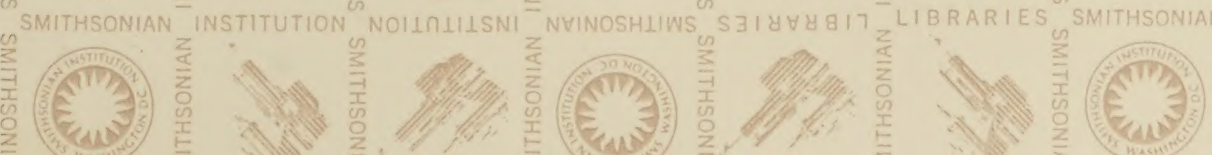






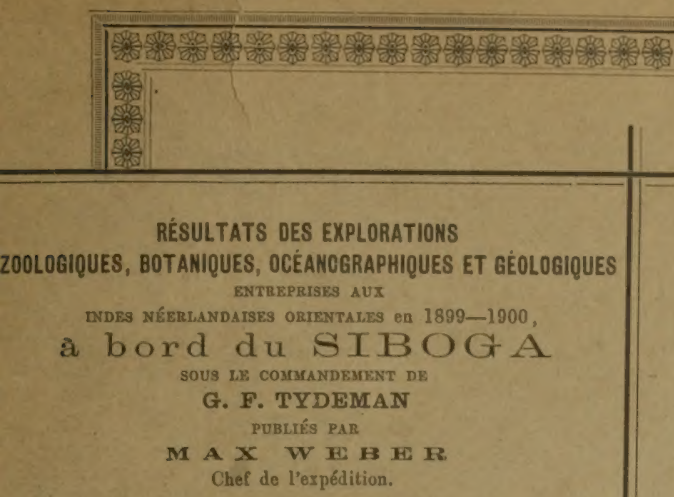

Litions

\section{RÉSULTATS DES EXPLORATIONS}

ZOOLOGIQUES, BOTANIQUES, OCÉANOGRAPHIQUES ET GËOLOGIQUUES BNTBEPRISES AUX

DNDES NÉBRLANDAISES ORIENTALES En 1899-1900,

a bord du SIBOG A SOUS UE COMMANDEMENT DE G. F. TYDEMAN PUBLÍ́s PAB

M A X W F H F R Chę de l'expédition.

\section{Siboga-Expeditie}

\#1. Introduction et description de l'expédition, Max Weber. *II. Le bateau et son équipement scieutifique, G. F. T y de ma a III. Résultats hydrograptiques, G. F. Ty de man.

IV. Koraminifera.

V. Radiolaria, M. Hartmann.

*VI. Porifera, G. C. J. Vosmaer et J. H. Vernhoul'). VII. Hydropolypi, Ch. Julin.

VIII. Hydrocorallinae, S. J. Hickson.

IX. Siphonophora, Mlea Lens et van Riemsdijk.

X. Hydromedusae, O. Mass.

XII. Scyphomednsae, 0 Mas.

*XII. Ctenophora, Mile F. Moser.

- XIII. Gorgonidae, Alcyonidae, J. Verslu ys ').

XIV. Pennatulidae, S. J. Hickson.

XV. Actinisria, P. Me Murrich.

*XVI. Madreporaria, A. Aleock ${ }^{2}$ ) et L. Döderlein.

XVII. Antipatharia, P. N. van K ampen.

XVIII. Turbellaria, L. von Graff et R. R. von Stummer.

XIX. Cestodes, J. W. S pengel.

XX. Nematodes, A. A. W. Hubrecht.

XXI. Chatognatha, G. H. Fow ler.

XXII. Nemertini, A. A. W. Hubrecht.

XXIII. Myzostomidae, R. R. von Stummer.

XXIVa. Polychaeta errantia, R. Horst.

XXIVb. Polychaeta sedentaria, M. Caullery et F. Mesnil.

*XXV. Gephyrea, C. Ph. Sluiter.

XXVI. Enteropueusta, J. W. Spengel.

XXVII. Brachiopoda, J. F. vau Bermelen.

XXVIII. Bryozos, S. F. Harmer.

XXIX. Copepoda, A. Scott.

XXX. Ostracoda, G. W. Müller.

XXXI. Cirrhipedia, P. P. C. Hoek.

XXXIIa. Isopoda, H. J. Han sen.

XXXIIb. Epicaridae, J. B onn ier.

XXXIII. Amphipoda, J. Bonnier.

XXXIV. Caprellidae, P. Mayer.

XXXV. Stomatopoda, H. J. Ha n sen.

XXXVI. Leptostracs, H. J. Hansen.

XXXVII. Sehizopoda, H. J. Hansen.

XXVIII. Sergestidae, H. J. Han sen.

XXXIX, Decapoda, J. G. de Man.

XL. Pantopoda, J. C. C, Loman.

XLI. Halobatidae, J. Th. Qu dem a n s.

XLII. Crinoiles, L. Dödorle in p p.

XLIII. Echinoidea, J. C. H, de Meyere

*XIIV. Holothurioidea, C. Ph. Slu iter.

XLV. Ophiuroidea, R. Köhler.

XLVI. Asteroidea, L. Döderlein.

XLVII. Solenogastres, H. F. Nierstrasz

XLVIII. Chitonidae, H. F. Nierstrasz.

XLIX. Prosobranchis, M. M. Schepman.

L. Opisthobranchia, R. Bergh.

LI. Heteropoda, J. J. Tesch.

III. Pteropoda, J. J. Tese h.

GII. Lamellibranchiata, P. Pelseneer et $\mathrm{Ph}, \mathrm{Da}$ atzen ber

IIV. Scaphopoda.

LV. Cephalopoda, L. Joubin.

ZVI. Tunicata, C. Ph. Sluifer.

LVII. Pisces, Max Weber.

LVIII. Cetacea, Max Weber

LIX. Liste des algues, Mmo A. Weber

* LX. Halimeda, Mille E. S. Barton. (Mmo E. S. Gepp).

LXI. Melobesieae, Mme A. Weber et M. Foslie.

IXII. Dinoflagellata. Coccosphaeridae, J. P. I, otsy.

LXIII. Diatomacese, J. P. Lotsy

LXIV. Deposita marina, O. B. Bōggil d.-

LXV. Résultats géologiques, A. Wi chmann.
DIE

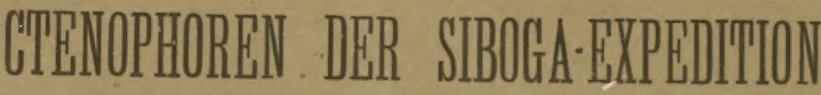

VON

FANNY MOSER

in Muinchen

Mit 4 Tafeln

Monographie XII aus

\section{UITKOMSTEN OP ZOOLOGISCH, BOTANISCH, OCEANOGRAPHISCH EN GEOLOGISCH GEBIED}

verzameld in Nederlandsch Oost-Indië r 899-1900

aan boord H. M. Siboga onder commando van

Luitenant ter zee ie kl. G. F. TYDEMAN

UITGEGEVEN DOOR

Dr. MAX WEBER

Prof, in Amsterdam, Leider der Expeditie

(met medewerking van de Maatschappij ter bevordering van het Natuurkundig onderzoek der Nederiandsche Koloniën)

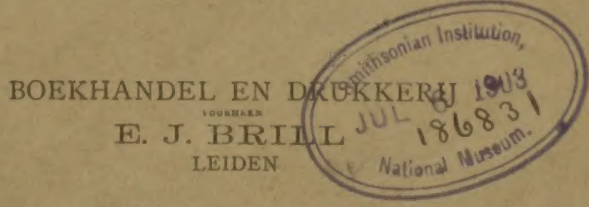




\section{Voor de uitgave van de resultaten der Siboga-Expeditie hebben bijdragen beschikbaar gesteld:}

De Maatschappij ter bevordering van het Natuurkundig Onderzoek der Nederlandsche. Koloniën.

Het Ministerie van Koloniën.

Het Ministerie van Binnenlandsche Zaken.

Het Koninklijk Zoologisch Genootschap "Natura Artis Magistra" te Amsterdam.

De ,Oostersche Handel en Reederij" te Amsterdam.

De Heer B. H. DE WAAL Oud-Consul-Generaal der Nederlanden te Kaapstad. 


\section{SIBOGA-EXPEDITIE.}




\section{Siboga-Expeditie}

\section{UITKOMSTEN}

OP

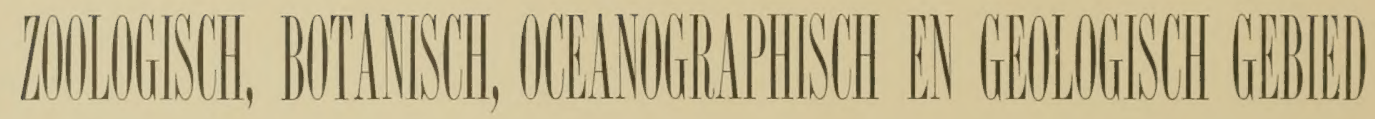

VERZAMELD IN

NEDERLANDSCH OOST-INDIË I899-I900

A AN BOORD H. M. SIBOGA ONDER COMMANDO VAN

Luitenant ter zee $1^{\mathrm{e}} \mathrm{kl}$. G. F. TYDEMAN

UITGEGEVEN DOOR

Dr. MAX WEBER

Prof. in Amsterdam, Leider der Expeditie

(met medewerking van de Maatschappij ter bevordering van het Natuurkundig onderzoek der Nederlandsche Koloniën)

BOEKHANDEL EN DRUKKERIJ

E. J. BRILI

LEIDEN 
Siboga-Expeditie XII

DIE

CTENOPHOREN DER SIBOGA-EXPEDITION

VON

$D^{R}$. FANNY MOSER

Mit 4 Tafeln

BUCHHANDIUNG UND DRUCKEREI

E. J. BIRILL

LEIIK:N - 1903 



\title{
DIE CTENOPHOREN DER SIBOGA-EXPEDITION
}

\author{
VON \\ Dr. FANNY MOSER \\ in Minchen.
}

Mit 4 TafeIn.

\section{VORIVORT.}

Die Kenntniss der Ctenophoren ist viel neueren Datums wie die der Medusen und Tunicaten. Der erste Fund reicht nicht weiter zurick als bis zum Jahre 1671, wo MERTExs im nördlichen atlantischen Ocean die ersten Melonenquallen fand und beschrieb. Dann verstrich ein volles Jahrhundert, bis sich ihm ein zweiter durch PATRICK Browx zugesellte. Jedoch erst im 19. Jahrhundert mehrten sich die Funde verhältnissmässig schnell, — doch relativ selten ist gutes Ctenophoren-Material auch jetzt noch geblieben.

Sowohl das späte Bekanntwerden wie diese Seltenheit ist leicht verständlich, wenn man sich vergegenwärtigt, wie schwer diese zarten, widerstandslosen Organismen in einigermassen gutem Zustand zu fangen und zu conserviren sind. Letzteres ist auch jetzt noch bei cinigen der empfindlichsten Formen, so der Eucharis unmöglich, da sie schon durch einen leichten Stoss in's Wasser zerfliessen. Die Tentakel gehen fast immer ganz verloren, oder erhailt sich nur ein Stummel derselben in der Scheide. Auch wird die Farbe zerstört und die Form clurch starke Contraction stark verindert.

So ist denn bei den Ctenophoren noch mehr wie bei anderen Organismen, wenn man von den Protozoen absieht, zur Kenntniss ihrer Organisation das Studium am lebenden Thiere ein unumgängliches Erforderniss. Das Bestimmen und Beschreiben von conservirtem Material kann daher immer nur eine provisorische Arbeit sein, bei der Irrtimer und Liicken unvermeidlich sind. Die Beschreibungen, unter Umständen selbst die systematische Stellung, werden, sobald lebendes Material vorliegrt, manche Aenderung und V'erbesserung erfahren missen.

Auf obengenannten Schwierigkeiten des Bestimmens und Beschreibens beruhen teilweise SIEOGA-EXPEUTIE XII. 
die in der Ctenophoren-Systematik noch immer vorherrschende Unklarheit. Sie hat aber noch andere Ursachen: I) und vor allem die so oft ganz ungenügenden und oberflächlichen Beschreibungen, besonders neueren Datums, die ein Wiedererkennen fast ausschliessen und mit daran Schuld sind, dass unter den verschiedensten Namen die gleichen Formen sich verstecken. Es ist das Verdienst CHux's die Synonima zusammengestellt und Ordnung in die Systematik der Ctenophoren gebracht zu haben. Doch auch in juingster Zeit sind wieder alte Formen unter neuen Namen beschrieben, neue Formen in falsche Gattungen, selbst Familien eingereiht worden. 2) In der ungenügenden Kenntniss der Weiterentwicklung der Jugendformen, so dass diese bisweilen als selbständige Arten beschrieben wurden, 3 ) in der kleinen Zahl der überhaupt bekannten Arten. Es giebt manche Gattungen mit einem einzigen Vertreter, der dann die Gattungsmerkmale liefert. Erst wenn sich diesem noch weitere Vertreter beigesellen, wird es möglich die eigentlichen Gattungsmerkmale auszuscheiden von dem, was der Species allein gehört. Einstweilen ist dem Forscher beim Bestimmen und Gruppiren noch eine gewisse Freiheit gelassen, die ein weiterer Grund zur Unordnung in der Systematik ist, insofern das Resultat des Bestimmens und der Ueberlegung, was als Gattungsmerkmal angesehen, was ausgeschieden werden soll, wenn man zur W Wahl zwischen zwei Merkmalen gezwungen ist, wie z.B. in dem auf Seite 9 beschriebenen Fall, ein verschiedenes sein wird, je nach dem Standpunkt des Betreffenden.

Um künftig die Arbeit des Bestimmens etwas zu erleichtern, werde ich mich im folgenden nicht darauf beschränken, die neuen Arten zu beschreiben. Ich werde immer jene Gruppen, die Vertreter unter dem Siboga-Naterial gefunden haben, und deshalb durchgearbeitet werden mussten, ausfiihrlich behandeln und kurze Beschreibungen aller bis jetzt bekannten, zu diesen gehörigen Arten geben ${ }^{1}$ ). Letztere sind den betreffenden Beschreibungen entnommen und so weit möglich aus den Abbildungen ergänzt worden, da oft einzelne Punkte nicht berücksichtigt wurden, die sich bei meinen Untersuchungen als nützlich erwiesen haben. Zu diesen zählen 1) die Höhe der Eintrittstelle der adradialen in die Meridionalgefässe, im Verhältniss zum Trichter; die Eintrittstelle kann steil über dem Trichter liegen, also nahe am Sinnespol, auf gleicher Höhe mit ihm, oder schräg über ihm, also ungefähr in der Mitte zwischen Trichterebene und Sinnespol. 2) die Lage dieser Eintrittstelle zur Rippenlänge, ob in deren Mitte, ihrer oralen oder aboralen Hälfte. Auch die Länge der Tentakelbasis und ihre Form verdienen Berücksichtigung. Den Beschreibungen sind kurze Differentialdiagnosen beigefügt und möchte ich hervorheben, wie sehr das Bestimmen erleichtert und Unsicherheit vermieden würde, wenn solche niemals der Beschreibung neuer Formen fehlten. Um hierfü ein Beispiel anzufihren die Bemerkung; dass die eigentliche Stellung der Bcrö̈ australis Mayer und ihre sehr wahrscheinliche Iclentität mit Bcrö̈ forskilii Chun sofort klar läge, wenn eben diese Differentialdiagnose vorhanden wäre. Ferner wurden, wo dies von CHus noch nicht geschehen konnte, die Unterscheidungsmerkmale der einzelnen Gattungen z.B. bei den Pleurobrachien und Hormiphoren zusammengestellt oder solche ergänzt.

Am Schluss wird eine kleine Bestimmungstabelle für die Pleurobrachiae und die lieroïdae beigefiigt.

1) Die im Siboga-Material nicht vorhandenen Arten sind durch ein vorgesetztes angedeutet. 
Beziiglich der einzelnen Bezeichnungen wurden die Cruy'schen Bezeichnungen Magenebene und Trichterebene beibehalten. Oben und unten, hinten und rorne, rechts und links wurden möglichst vermieden, da hierin zwischen Agassiz, Cuux und Anderen keine Uebercinstimmung herrscht. Ferner werden, mit Cuux, als subventrale Rippen jene zu beiden Seiten des Magens, also in der Magenebene befindlichen Rippen bezeichnet, auch bei den Beroïden, wo dann die Polplatte die Lage der Magenebene, angiebt; in der Trichterebene liegen clie Subtentacularen Rippen.

Was die Längenverhältnisse anbelangt, so werden der Magen und damit auch das Trichtergefäss als mittelgross bezeichnet, wenn sie die Körpermitte erreichen, als kurz, wonn dies nicht der Fall ist, als lang, wenn sie diese überschreiten - einem langen Magen entspricht dann immer ein kurzer Trichter und umgekehrt. 
$I^{\mathrm{e}}$ Ordnung: CYDIPPIDAE Lesson.

Callianiridae Eschsch. Syst. d. Akal. p. 21, 1829.

Cydippae Lesson, Hist. nat. Zooph. Akal. p. 100, I843.

Cydippidae Gegenbaur, Arch. f. Naturg. p. 196, 1856 .

Saccatae L. Agassiz, Contrib. N. H. U. St. Vol. III, p. 193, I860.

Saccatae A. Agassiz, Illustr. Cat. Vol. II, p. 26, I865.

Cy'dippidac Chun, Fauna u. Flora d. Golfs v. Neapel. p. 273 , I880.

Kuglige, cylindrische, comprimirte, oder mit flügelförmigen Fortsätzen am Sinnespol versehene Rippenquallen, mit zwei einfachen oder gefiederten, meist in eine Scheide zurückziehbaren Senkfäden und blind endigenden Meridional- und Magengefässen.

i Familie: Pleurobrachiadae Chun.

Cydippidae L. Agassiz, Contrib. N. H. U. St. Vol. III, p. 196, 293, I860.

Cydippidac A. Agassiz, Illustr. cat. No II, p. 29, I865.

Pleurobrachiadae Chun, Fauna u. Flora des Golfs v. Neapel. p. 276, 280 , I88o.

Körper im Querschnitt meist rund; Rippen von gleicher Länge; Flügelfortsätze am Sinnespol fehlen; Tentakel mit einfachen, heteromorphen oder ganz fehlenden Seitenfäden.

Die Familie der Pleurobrachiadae zerfallt nach Cruv in zwei Gruppen: die mit rundlichen und die mit cylindrischen Formen. Diese Merkmale haben aber wenig praktische Bedeutung da I) diese Formen so in einander ubergehen, dass es meist schwer ist zu sagen, mit welcher man es zu thun hat, wie schon aus den CHus'schen Abbildungen hervorgeht. (Vergl. Fauna und Flora d. Golfs von Neapel Taf. I, Fig. I mit Ctenophoren der Plankton-Expedition I 898 , Taf. III, Fig. 2). 2) wird die Form durch verschiedene Contractionszustände und durch das Alter stark verändert, vor Allem aber durch die Conservirung. So wäre es an dem vorliegenden Material theilweise unmöglich gewesen, nach der äusseren Form eine Gruppirung vorzunehmen; hingegen giebt es ein anderes Merkmal, nach welchem diese, auch bei conservirtem Material, ziemlich leicht ist, nämlich nach der Länge der Meridionalgefässe. Bei der einen Gruppe, den Pleurobrachiadae ovatae Chun, reichen die Meridionalgefïsse nicht bis zum Mundrand; dabei sind sie entweder von gleicher Länge wie die Rippen, oder etwas länger. Bei der anderen Gruppe, den Pleurobrachiadae cylindricae Chun, reichen die Meridionalgefisse bis zum Mundrand, 
ebenfalls ganz oder nur theilweise von den Rippen bedeckt. Dic 4 Genera vertheilen sich auf diese 2 Gruppen in gleicher Weise, wie bei Cnux und haben wir darnach:

Gruppe a) Meridionalgefässe nicht bis zum Munde reichend.

(Pleurobrachiadae ovatae Chun).

Genus Pleurobrachia.

Genus Hormiphora.

Gruppe b) Meridionalgefässe bis zum Munde reichend.

(Pleurobrachiadae cylindricae Chun).

Genus Lampetia.

Genus Euplokamis.

Gruppe a) Meridionalgefässe nicht bis zum Munde reichend.

Ie Genus Pleurobrachia Iileming.

Pleurobrachic Flening, Philos, of Zool, II, p. 6ז2.

Cydippe Eschsch., Syst. d. Akal. p. 29, I829.

Pleurobrachiz L. Agassiz, Mem. Am. Acad. IV, p. 314, 1849.

Pleurobrachia L. Agassiz, Contr. nat. Hist. U. St. III, p. 293, I860.

Pleurobrachica A. Agassiz, Illustr. Catal. No II, p. 29, I\$65.

Cydippe Lesson, Hist. Nat. d. Zooph. Acal. p. 104, I843.

Tentakelbasis, bei geschlechtsreifen Thieren, zwischen Magen und Körperoberfläche. Tentakelaustritt auf gleicher Höhe mit dem Trichter oder zwischen letzterem und dem Sinnespol.

Die Lage der Tentakelbasis zwischen Magen und Körperoberfläche ist der einzige Unterschied von Hormiphora, ein Unterschied, der bei jungen Thieren in Wegfall kommt, ebenso bei sehr kleinen Formen, wo alle Organe so dicht zusammengedrängt sind, dass es schwer ist zu entscheiden, ob die Tentakelbasis eigentlich dem Magen anliegt oder nicht. Der von CHux noch genannte Unterschied, der sich auf die Nebenfïden der Tentakeln stïtzt, lïsst sich nicht halten, wie später gezeigt wird.

Es sind bis jetzt bekannt 3 Arten, nämlich Pleurobrachia pileus Fabricius, Plcurobrachia rhodopis Chun und Plenrobrachia bachei Agassiz, von denen ich kurze Beschreibungen anbei folgen lasse. $\mathrm{Zu}$ diesen gesellen sich jetzt als neu hinzu Plcurobraclia globosa und Plcurobrachia pigmentata.

Die von MAyer beschriebene Plarrobrachia ochracia ist, wie später gezeigt wird, keine Plaurobrachia, sondern eine Hormiphora und wird demgemiss bei diesen beschrieben werden.

*1. Pleurobrachia pileus Fabricius.

Berö̈ pilcus Fabricius, Fauna Groenl. No 354 . p. $36 \mathrm{r}, 1750$.

Berö̈ pileus Modecr, Kongl. Vet. Acad. N. Handl. VII, P. 43, 1790

Berö̈ pileus Fileming, p. 504,1828 .

Cydippe pileus Iischisch., Syst. d. Akal. p. 24, I829. 
Cydiffe bicolor M. Sars, Beskriv, og Iagdtag. over nogle maerk, eller nye i. Havet ved. d. Bergenske Kyst levende Dyr. p. 35, i 835 .

Cydippe pomiformis Pattersen, Trans. Roy. Irish Acad. V, 19. p. $9 \mathrm{I}-\mathrm{IOS}, 1838$.

Cydippe pileus Lesson, Hist. Nat. d. Zooph. Acal. p. 105, I\$43.

Pleurobrachia rhododactyla L. Agassiz. Mem. Am. Acad. IV, p. 314, I\$49.

Pleurobrachic rhododactyla L. Agassiz, Contr. Nat. Hist. U. St. III, p. 203, 294, I860.

Pleurobrachia rhododactyla A. Agassiz, North. Amer. Acal. P. 30 Mus. of. Comp. Zool. Harvard Coll. N. II, 1865.

Cydippe pilens Mörch, Naturh. Bidr. til en Beskr. af Grönland. p. 97, I857.

Cy'dippe pileus Claus, Bem. über Cten. u. Med. Zeitschr. f. wiss. Zool. V, I4. p. 384,1864 .

Pleurobrachic pileus Vanhöffen, d. grönl. Cten. Bibl. Zool. H. 20. p. 21, I895.

Plenrobrachia pileus Chun, d. Bez. zw. d. arkt. u. antarkt. Plankton p. 21, I897.

Plcurobrachia pileus Chun, d. Cten. d. Plankton Exped. p. I5, ISgS.

$2-9 \mathrm{~mm}$.

Körper eiförmig, gegen den Sinnespol etwas verjüngt, in der Magenebene schwach comprimirt. Rippen nahe am Sinnespol beginnend, reichen bis zum oralen Viertel, also ziemlich lang; Meridionalgefässe gleich lang wie die Rippen. Magen von mittlerer Grösse. Eintritt der adradialen Gefässe in die Meridionalgefässe steil über dem Trichter, also nahe am Sinnespol; im obern drittel der Rippen, dieser Eintrittstelle und damit dem Sinnespol sehr nahe gerückt, liegt die Scheidenöffnung. Scheide lang, Tentakelbasis gestreckt, ziemlich lang, schräg zwischen Körperoberfläche und Magen. Tentakel mit Nebenfäden.

Arktisches Stromgebiet; Ostküste von Nordamerika; Nord- und Ostsee; Ausläufer des Labradorstromes.

2. Pleurobrachia rhodopis Chun.

Pleurobrachia rhodopis Chun, Fauna u. Flora d. Golfs v. Neapel. p. 2S2, ISSo.

$5,7 \mathrm{~mm}$.

Körper eiförmig, gegen den Sinnespol etwas verjüngt. Rippen in einiger Entfernung vom Sinnespol beginnend, reichen nur bis zum oralen Drittel, also ziemlich kurz. Meridionalgefässe von gleicher Länge wie die Rippen. Magen lang, Trichtergefäss $1 / 3$ der Körperlänge, konisch verjingt gegen den sinnespol. Eintritt der adradialen in die. Iferidionalgefisse auf grleicher Höhe mit dem Trichter, in der Mitte der Rippen; auf gleicher Höhe liegt die Scheidenöffnung, also in ziemlicher Entfernung vom Sinnespol. Scheide kurz, Tentakelbasis nicht lang, schräg, zwischen Körperoberfläche und Nagen. Tentakel mit Nebenfäden.

Der Hauptunterschied von Pleurobrachia pilcus Fabr. liegt in den sehr kurzen Rippen und Meridionalgefassen und der Lage der Eintrittstelle der adradialen in die Meridionalgefässe, die sich auf gleicher Höhe mit dem Trichter befindet.

Mittelmeer.

3. Plarobrachia bachci Agassiz.

Plcurobrachia bachci L. Agassiz, Contr. Nat. Hist. U. St. III, p. 294, IS60.

Pleurobrachia bachci A. Agassiz, Illustr. Catal. No II, p. 34, 1865. 
Ungenuigend beschrieben. Aehnlich Platrobrachia pileus Fabr. (Plourobrachiu rhododact. Agassiz) jedoch längeres Trichtergefiss, kiirzerer Magen. Scheidenöffnung entfernter vom Sinnespol, unter der Eintrittstelle der adradialen in die Meridionalgefisse.

4. Pleurobrachia globosa nov. spec. Taf. I, Fig. I- 4.

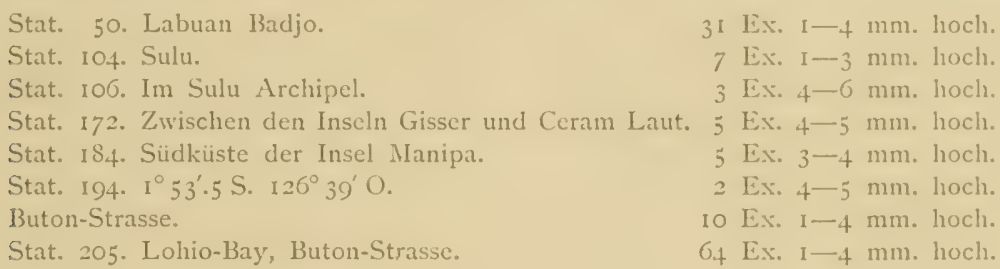

I- $6 \mathrm{~mm}$.

Es lagen über roo Exemplare vor, die meisten in Formol schön conservirt, wïhrend clie in Alkohol stark gelitten hatten. Die Kleinsten von $I-2,5 \mathrm{~mm}$. zeigten noch ganz larvales Verhalten, während von $2,5 \mathrm{~mm}$. an schon ausgebildete Verhältnisse vorlagen, so dass zwischen 2,5 und $6 \mathrm{~mm}$. nur Grössenunterschiede bestanden.

Der sehr durchsichtige, glashelle Körper ist fast kugelig, weder am oralen noch am aboralen Pole verjüngt. Am meisten fallen der kurze, die Kü̈perhälfte nicht erreichende Magen, und die, schon auf der Höhe seiner aboralen Grenze endigenden und ziemlich entfernt rom Sinnespol beginnenden, sehr kleinen Rippen auf wie auch zwei dunkle, rundliche Kerne, die iiber dem Magen, zwischen Trichter und Körperoberfläche liegen. Letztere stellen sich, bei näherer Untersuchung, als die fast kugligen Tentakelbasen heraus. Die Tentakel haben einfache Nebenfäden; die Scheiden liegen schräg zwischen Trichtergefäss und Körperoberfläche und ihre Oeffnung auf gleicher Höhe oder etwas iiber dem aboralen Anfang der Rippen, welche, bei clen grössten Exemplaren, 9 Schwimmplattchen mit nicht sehr langen Wimpern besitzen. Die Meridionalgefässe sind von gleicher Länge wie die Rippen und dic Eintrittstelle der adradialen Gefisse befindet sich in deren unterem Drittel, schräg iber dem Trichter. Das Trichtergefiss ist sehr lang und schlank, der Sinneskörper ziemlich tief eingesenkt. Die Contraktionszustïnde des Mundes waren zu verschieden um einen sichern Schluss auf seine natirliche fForm zu erlauben. Die älteren Exemplare waren geschlechtsreif und die Geschlechtsprodukte in den Gefissen so angeordnet, dass die Eier nach innen, das Sperma nach der Körperoberfliche zu lagen — nur selten war die Anordnung eine theilweis seitliche.

Bei den jüngsten Larven ist die Körperform eine mehr konische, gegen den oralen l’ol verjüngte; die Rippen sind ganz kurz und zählten als Minimum 6 Schwimmpliittchen. Je iifter die Larven sind, je mehr nähern sie sich der Kungelform, unter gleichzeitiger Verlingerung der Rippen.

Der Unterschied zwischen Plarrobrachia globosa und den iibrigen, bis jetzt bekannten Pleurobrachien liegt in der kugeligen Form, den sehr kleinen, die aborale Magengrenze nicht erreichenden Rippen, dem kurzen Magen und langen, schlanken Trichtergefiss. Fierner in den hochgelegenen, kugligen, kleinen Tentakelbasen, dem tiefgelegenen Eintritt der adradialen in 
die Meridionalgefässe, der im unteren Drittel der Rippe stattfindet, während bei Pleurobrachica pilcus im oberen Drittel, bei Plaurobrachia rhododactyla in der Mitte derselben; und schliesslich unterscheidet sich Pleurobrachia globosa noch durch die an der aboralen Grenze des Rippenfeldes befindliche Scheidenöffnung.

Indo-Malayisch.

5. Plenrobraclica pigmentata nov. spec. Taf. I, Fig. 5 und 6. Taf. IV, Fig. I-3.

Stat. 165. Ostküste von Misool.

9 Ex. $2-6 \mathrm{~mm}$.

Stat. 172. Zwischen den Inseln Gisser u. Ceram Laut I Ex. $5 \mathrm{~mm}$.

$2-6 \mathrm{~mm}$.

Von den io Exemplaren war leider nur das Eine, in verdünntem Formol conservirt, leidlich gut erhalten. Die anderen in Spiritus hatten sehr gelitten.

An dieser neuen Art ist ein dunkler Streifen das Auffälligste, der sich in der Mitte jeden Schwimmplättchens befindet und den beiden Rippen ein streifiges Aussehen verleiht. Diese Streifen rühren von dunkelbraunem Pigment her, das sich am peripheren Ende der Zellen, in der Mitte des Schwimmplättchens befindet, dicht über der Abgangsstelle der Wimpern und welches, wie ein dunkles Band, die ganze Breite des Plättchens durchzieht. Diesem auffallenden Merkmale ist der Speziesname entlehnt.

Der Körper ist cylindrisch, schwach in der Nagenebene abgeplattet, gegen den Sinnespol etwas verjünt, unterhalb des zweiten Drittels eingeschnürt, so dass der orale Theil wie eine Krause vorspringt. Der Mund ist eine ziemlich weite, mehr rundliche Oeffnung, von zwei krausenartigen Lippen begrenzt, die in der Trichterebene liegen. Die Rippen beginnen dicht am Sinnespol und reichen bis zur Einschnürungsstelle, sind also ziemlich lang. Sie sind einander paarweise genähert, sehr dick und breit, so dass nur wenig freier Raum zwischen ihnen übrig bleibt und die inneren Organe kaum sichtbar sind. Die Schwimmplättchen stehen dicht bei einander und die Cilien gehen nicht als einheitliches Packetchen ab, sondern zeigen eine Dreitheilung und zwar so, dass die mittleren Wimpern von jedem Schwimmplättchen senkrecht zur Körperoberflïche, also geradeaus abgehen, während die aboralen Wimpern sich aboral, die oralen oralwärts krümmen, wie auf der Abbildung (Taf. IV, Fig. 2) ersichtlich. Dicht über den aboralen Wimpern befindet sich der Pigmentstreif. Dass diese Dreitheilung nur von der Conservirung herrihrt scheint nicht wahrscheinlich. Die Meridionalgefässe sind von gleicher Länge wie die Rippen, der Magen von mittlerer Grösse, das Trichtergefäss ein dünnes Rohr. Wo der Eintritt der adradialen in die Mericlionalgefässe stattfindet liess sich nicht feststellen. Die lange, oralwärts verschmälerte Tentakelbasis liegt sehr weit unten, nahe bei der Einschnirungsstelle, schrïg zwischen Magen und Körperoberfläche; die Scheidenöffnung befindet sich in der Mitte, zwischen dem Trichter und dem ziemlich eingesenkten Sinnespol. Das Magenepithel zeigt in der Trichterebene jederseits einen Bischel faltiger Erhebungen, in denen die Zellen grösser sind. Diese Büschel kann man füglich Leber nennen. Die Geschlechtsorgane sind halbseitig angeordnet. Tentakel waren nicht erhalten. Dic älteren Exemplare sind mehr cylindrisch wie die jüngeren. 
Nach der cylindrischen Form misste Plenrobrachia pigmentata in die zweite Cnuv'sche Gruppe, (b) die der Pleurobrachiae cylindricae), eingereiht werden; hiegegen spricht aber schon der allgemeine Habitus, sowie die Kürze der Meridionalgefisse, welche den Mundrand nicht erreichen. Letzteres Merkmal findet sich ausschliesslich bei den, bis jetzt bekannten, unter Gruppe a) befindlichen Pleurobrachien, so dass auch die neue Species, trotz ihrer cylindrischen Form, in diese Gruppe eingereiht werden muss. Zur Gattung Plourobrachia gehört sie wegen der Lage der Tentakelbasen: schräg, zwischen Körperoberfäche und Magen. Sie unterscheidet sich von den bisher bekannten Pleurobrachiae nicht nur durch ihre Form, sondern vor Allem durch die, bis jetz noch nirgends beobachteten Pignentstreifen in den Rippen; ferner durch die breiten, dicht stehenden, paarweise angeordneten Rippen, die den Körper fast undurchsichtig erscheinen lassen, und durch die Einschnürung am oralen Körperdrittel, welches dadurch wie eine Krause aussieht. Auch die tief unten beginnenden Tentakelbasen bilden ein Unterscheidungsmerkmal.

Es wäre ja immerhin möglich dass diese Form schon beschrieben wurde, unter einem anderen Namen, jedoch konnte ich in der Litteratur nichts hieriiber finden.

Indo-Malayisch.

2e Genus Hormiphora L. Agassiz.

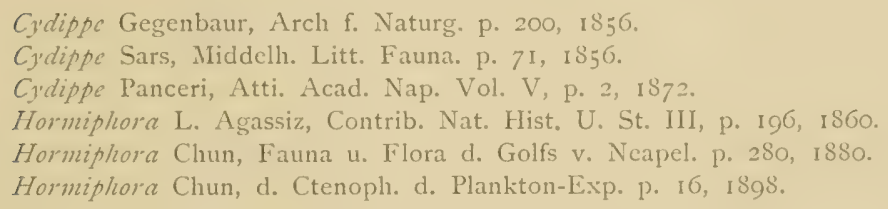

Tentakelbasis gerade, dem Magen dicht angelagert. T'entakelaustritt auf gleicher Höhe wie der Trichter, oder zwischen diesem und dem Sinnespol.

Ausser dem, auf Lage der Tentakelbasis beruhenden Unterschied zwischen Plcurobrachia und Hormiphora nennt CHux, als weiteres Unterscheidungsmerkmal, die zweierlei Formen von Seitenfäden an den Tentakeln der letzteren. Die einen sind einfach fadeuförmig, die anderen von bizarrer, eolidenförmiger Gestalt. Dieses Unterscheidungsmerkmal entbehrt der praktischen Bedeutung erstens, weil letztere Anhänge mit dem Alter schwinden, wie Cinus selbst mit ziemlicher Sicherheit annimmt, ferner weil sie sich bei conservirten Thieren so stark contrahiren, dass sie bis zur Unkenntlichkeit schrumpfen. In den meisten Fällen aber sind die Tentakel überhaupt nicht erhalten, daher eine Systematik, die Form, Zahl und Anordnung der Tentakel eine wichtige Rolle zuweist, von vorneherein wenig brauchbar.

Hier giebt es aber gewisse Formen, die meiner Meinung nach entschieden zur Familie der Pleurobrachiadae und unter dieser zur Gruppe a) gehören, wegen der kurzen, den Mundrand nicht erreichenden Meridionalgefasse, so z.B. die Hormiphora achraca, die Hormiphora fusiformis, die Hormiphora sibogac; diese haben aber einerseits die Tentakelbasen dem Magen dicht angelagert, müssten daher zur Gattung IIormiphora grehören, andrerseits aber entbehren ihre Tentakel entweder iiberhaupt der Seitenfaden, oder haben nur einfache, so dass man sic wegen des Mangels an heteromorphen Anhängen der Gattung Plcurolrachia zurechnen misste. 
Da man in diesen Fällen zwischen den zwei Merkmalen: Lage der Tentakelbasis und eolidenförmigen Tentakelanhängen zu wählen hat, wird man sich für das Erstere entscheiden muissen, das allein immer, wenn es sich nicht um ganz junge, oder sehr kleine Exemplare handelt, auch bei nicht gut conservirtem Material, leicht erkennbar ist. Dementsprechend müssen aber auch künftig die eolidenförmigen Tentakelanhänge als Gattungsmerkmal der Hormiphora gestrichen und auch solche Formen, die entweder gar keine oder nur einfache Anhänge haben, zu dieser gerechnet werden. Ob der dadurch allein übrig bleibende Unterschied zwischen Plcurobrachia und Hormiphora, die Lage der Tentakelbasis, genügt um zwei verschiedene Gattungen zu machen, scheint doch sehr fraglich. Bis aber das Ctenophoren-Naterial ein umfangreicheres ist und durch neue Funde ihre verschiedenen Entwicklungsstadien besser bekannt, hat eine Revision der Systematik wenig Wert. Sie wäre doch nur eine provisorische Arbeit, die erst später mit einem gewissen Erfolg vorzunehmen sein wird.

Beschrieben wurden bis jetzt 5 Arten, nämlich Hormiphora plumosa Agassiz, Hormiphora spatulata Chun, Hormiphora palmata Chun, und 2 Arten, Hormiphora ochracea, unter dem Namen Plarobrachia ochracea Mayer und Hormiphora fusiformis als Lampetia fusiformis Nayer. Ich lasse, zur Erleichterung künftiger Bestimmung, die theilweise ergänzten und vervollständigten Beschreibungen dieser 5 Arten folgen, zu denen auch eine neue Art, Hormiphora sibogac, hinzukommt.

i. Hormiphora plumosa L. Agassiz.

Cy'dippe hormiphora Gegenbaur, Arch. f. Naturh. p. 200, I856.

Cydippe plumosa MI. Sars, Middelhavets Litt. Fauna. p. 71, 1856.

Hormiphora plumosa L. Agassiz, Contrib. Nat. Hist. U. St. III, p. 196.

Cydippe densa Spagnolini, Cat. Ber. Golfs d. Nap. Bull. d. Nat. e. Med. nap. p. 61, IS70.

Cyrlippe densa Panceri, La luce egli org. lum. d. Beroidei Atti. R. Accad. Se. Fis. et Mat.

Nap. V, p. 2.

Hormiphora phumosa Chun, Fauna u. Flora d. Golfs v. Neapel. p. 28 r, I880.

Gr. 5-20 $\mathrm{mm}$.

Körper eiförmig, gegen den oralen Pol stark verjüngt. MIund von 2 Lippen begrenzt, die in der Trichterebene liegen. Rippen schmal, in einiger Entfernung vom Sinnespol beginnend, reichen etwas über das orale Drittel. Die Meridionalgefässe sind von gleicher Länge wie sie. IIagen lang, über $/ / 3$ der Körperlänge, daher Trichtergefäss kurz, sich konisch gegen den Sinnespol verjüngend. Eintritt der adradialen in die Meridionalgefasse auf gleicher Höhe wie der Trichter, aboral von der Mitte der Rippen. Scheidenöffnung etwas über dieser Eintrittstelle, auf der Grenze des oberen Drittels der Rippen. Tentakelbasis lang, senkrecht gestellt, dem Magen dicht angelagert. Scheide voluminös. Tentakel mit gelben, eolidenförmigen Nebenfïien. Braunpigmentirte Magenwuilste, sonst farblos, durchsichtig.

Mlittelmeer.

2. Hormiphora spatulata Chun.

Hormiphora spatulata Chun, d. Ctenoph. d. Plankton-Exped. p. 1S, ISgS. 
$8-21 \mathrm{~mm}$.

Körper cylindrisch, an beiden P'olen etwas verjüngt. Langgezogene, breite Rippen beginnen in der Nähe des Simnespols und erstrecken sich bis in die Nähe des Mundes. Die Meridionalgefässe sind noch etwas linger. Nagen gross, iber die Hälfte der Körperliinge reichend. Trichtergefiss enges, nach oben sich nur wenig verschmailerndes Rohr. Eintritt der adradialen in die Meridionalgefisse schräg über dem Trichter, im aboralen Sechstel der Rijpe. Scheidenöffnung zwischen diesem und dem Sinnespol. Scheide ziemlich lang und voluminüs. Tentakelbasis dem Magen nicht ganz dicht angeschmiegt, oralwärts etwas divergirend. Tentakel mit einfachen Seitenfiden.

Hormiphora spatulata unterscheidet sich von Ilormiphora plumosa durch die kürzeren, dem Magen nicht dicht angeschmiegten, oral divergirenden Tentakelbasen, die kleineren Scheiden, die schräg über dem Trıchter liegende Eintrittstelle der adradialen in die Meridionalgefisse und die an der Grenze des aboralen Körpersechstel liegende Scheidenöffnung.

Mediterran-Atlantisch. (Orotava, Meerenge von Gibraltar).

\section{Hormiphora palmata Chun.}

Hormiphora palmata Chun, Bericht über eine nach d. Kanar. Inseln im Winter IS87/188S ausgef. Reise. Sitz. Ber. Akad. IViss. Berlin. XXX, p. 525, 1889.

Hormiphora palmata Chun, d. Ctenoph. d. Plankton-Exp. 1) 17, I\$gS.

$\mathrm{I} 4-21 \mathrm{~mm}$.

Körper sehr langgezogen cylindrisch (fast doppelt so lang wie breit); gegen die beiden Pole etwas verjügt; Rippen schmal und lang, in der Nähe des Sinnespols beginnend und bis in die Nähe des Mundes reichend; die Meridionalgefässe sind kaum länger wie sie. Magen lang, Trichtergefäss schlankes, nach oben sich wenig verjüngendes Rohr. Eintritt der adradialen, in die Meridionalgefässe auf gleicher Höhe wie der Trichter, im aboralen Drittel der Rippen. Scheidenöffnung etwas höher, auf der Grenze des aboralen Körperviertels, also in ziemlicher Entfernung vom Sinnespol. Scheide sehr lang und sehr voluminös. Tentakelbasis dem Mlagen dicht angeschmiegt und sehr lang. Tentakel wahrscheinlich einerlei Seitenfiden.

Vermuthlich hierher zu rechnen sind eine Anzahl Larven von $5-6 \mathrm{~mm}$. die Cirus bei Orotava fand. Sie gleichen sehr der Larve von Pleurobrachia globosa durch ihre eiförmige, gegen den oralen Pol stark zugespitzte Form und die kurzen, iiber der Mitte des Körpers verlaufenden Rippen. Sie unterscheiden sich von ihr durch den langen Magen, die langen, diesem dicht angeschmiegten Tentakelbasen, grossen Scheiden und die bizarren, grossen, eolidenförmigen Anhänge der Tentakel. Diese Anhänge sind herzförmig mit verschiedenartigen Fortsätzen versehen und von gelber oder bräunlicher Färbung.

Die jüngsten Larven von $3 \mathrm{~mm}$, entbehrten noch ganz dieser Anlänge, oder besassen nur einen am Ende des Tentakels.

Hormiphora palmata unterscheidet sich von Hormiphora plumosa und spatulata durch die lang gestreckte, cylindrische liorm, durch die sehr voluminösen, langen Scheiden und Tentakelbasen. Im Speziellen unterscheidet sie sich von Ersterer durch die langen Rippen, von 
Letzterer durch die dem Magen dicht angeschmiegten Tentakelbasen und die auf gleicher Höhe mit dem Trichter gelegene Einmündungsstelle der adradialen in der Meridionalgefässe.

Atlantisch (Cap Verde, Orotava).

4. Hormiphora fusiformis (Nayer).

Lampetia fusiformis A. G. Mayer, Medusae Mus. of Comp. Zool. Harvard. Coll. V. XXVI, N' 3. 1102, 1. 1, I.

4o min.

Körper langestreckt, cylindrisch, oraler Pol langgezogen verjüngt, der aborale stumpf; in der Magenebene comprimirt. Die sehr schmalen Rippen beginnen nahe am Sinnespol und reichen bis zur Grenze des oralen Körperdrittels. Die Schwimmplättchen stehen sehr dicht und sind deren ca. 40 vorhanden. Die Meridionalgefässe sind von gleicher Länge wie die Rippen. Nagen mittelgross; Trichtergefäss schlank, in der Mitte etwas erweitert. Eintritt der adradialen in die Meridionalgefässe schräg über dem Trichter. Scheidenöffnung über diesem, an der Grenze des oralen Körperviertels. Scheide sehr lang, schlank, zierlich geschwungen; Tentakelbasis lang, dem Magen dicht angeschmiegt. Tentakel mit einfachen Nebenfäden.

Dass Hormiphora fusiformis thatsächlich eine Hormiphora und keine Lampetia ist, geht deutlich aus den, den Mundrand nicht erreichenden Meridionalgefässen hervor, ferner aus dem allgemeinen Habitus, sowie Lage und Form der Tentakelbasen und Scheiden. Warum MAYER aus ihr eine Lampctia gemacht hat, ist aus seiner sehr ungenügenden Beschreibung, der auch eine Differentialdiagnose gänzlich fehlt, nicht ersichtlich, um so weniger, als er eine andere Art, Hormiphora ochracea, die ihr in allem Wesentlichen so ähnlich ist, dass beide notwendig zu der gleichen Gattungen gehören miissen, als Plourobrachia ochracca bestimmt hat - was der Lage der Tentakelbasen wegen ebenfalls unmöglich ist.

Hormiphora fusiformis unterscheidet sich von den übrigen Hormiphora-Arten durch ihre langgezogene Gestalt, den langgezogenen, allmählich sich verjügenden oralen Pol, und die graziös geschwungenen, schlanken, langen Scheiden. Im Speziellen unterscheidet sie sich von Hormiphora spatulata und palmata durch die viel kürzeren Rippen und Meridionalgefässe, von letzterer und Hormiphora plumosa durch die, nicht auf gleicher Höhe mit dem Trichter, sondern schrä̀g über diesem befindliche Eintrittstelle der adradialen in die Meridionalgefässe.

Obige Beschreibung von Hormiphora fusiformis ist, so gut es ging, aus der MAYER'schen Beschreibung und seinen Abbildungen zusammen gestellt.

Tropisch Pacifisch.

\section{Hormiphora ochracea Mayer.}

Pleurobrachia ochracea Mayer, Medusac IIus. Comp. Zool. Harvard Coll. Vol. XXVI, N" 3 . p. $170,1902$.

Stat. 122. $1^{\circ} 58^{\prime} .5$ N., $125^{\circ} 0^{\prime} .50$. I Ex. $35 \mathrm{~mm}$.

Stat. 95. $5^{\circ} 43^{\prime} .5$ N., $110^{\circ} 40^{\prime} .0$. I Ex. I6 mm.

Stat. 14.4. Nördl. d. Insel Damar. I Ex. $15 \mathrm{~mm}$. 
12 - $35 \mathrm{~mm}$.

Körper cylindrisch, an den beiden Polen etwas verjingt. Rippen in einiger Enfernung vom Sinnespol beginnend, reichen kaum über die Hälfte des Körpers, also kurz. Die Meridional. gefässe sind-bedeutend länger und erreichen die Grenze des oralen Körperdrittels. Magen sehr lang, das aborale Körperdrittel ïberschreitend; Trichtergefiss kurz, schlank. Eintritt der adradialen in die Meridionalgefisse auf gleicher Höhe mit dem Trichter, im aboralen Viertel der Rippe. Scheidenöffnung im aboralen Körperdrittel, noch innerhalb des Rippenfeldes. Scheiden sehr lang, voluminös. Tentakelbasen sehr lang, dem Magen dicht angelagert. Tentakel dick, ohne Seitenfäden. Nur bei dem jüngsten Exemplar von $1,5 \mathrm{~cm}$. fand ich in dem, nocin in der Scheide steckenden, allein erhaltenen Theil des Tentakel, fadenförmige Seitenfaden, woraus vielleicht geschlossen werden darf, dass letztere mit dem Alter verloren gingen. Das von MLYER beschriebene Exemplar hat nur $12 \mathrm{~mm}$. und zeigt als einzigen Unterschied, von den oben beschriebenen grösseren Exemplaren, eine mehr ciförmige Gestalt, was gewiss nur auf den Altersunterschied zurickzuführen ist, so dass es kaum zweifelhaft sein kann, dass beide Formen zusammen gehören, jedoch nicht zur Gattung Plcurobrachia, sondern zur Gattung Hormiphora, wie aus der Lage der Tentakelbasen deutlich hervorgeht. Der Mangel an heteromorphen Seitenfäden kann, wie früher gezeigt wurde, kaum dagegen angefuhrt werden.

Ein weiterer Unterschied der Plaurobrachia ochracca Mayer von meiner Hormiphora ochraca liegt in dem Abgang des Tentakels von der Tentakelbasis, nämlich von deren oralem Ende, statt von der Mitte derselben. Da dies aber bei keiner der ibrigen, von mir untersuchten Cydippen der Fall ist, sondern die Tentakel immer von der Mitte der Tentakelbasis abgehen, kann dies wohl nur durch ungenügende Beobachtung erklärt werden und keinen Einwand geben, dass beide Formen nicht die gleichen seien.

Hormiphora ochracea ist kenntlich an den kurzen Rippen und sehr langen Meridionalgefässen; von Hormiphora spatulata und fusiformis unterscheidet sie sich ausserdem durch die, auf gleicher Höhe mit dem Trichter liegende Eintrittstelle der adradialen in die Meridionalgrefisse.

Tropisch Pacifisch. Indo-Malayisch.

6. Hormiphora sibogae nov. spec. Taf. II, Fig. $1-3$.

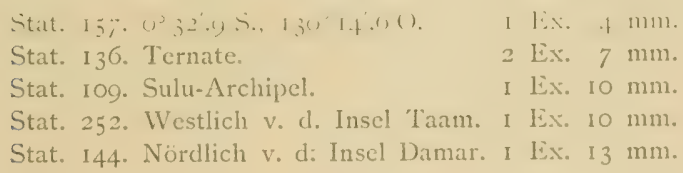

Körper cylindrisch, am oralen Pol nur wenig verjüngt, schwach comprimirt in der Magenebene. Rippen breit, sehr nahe am Sinnespol beginnend und bis zur oralen Grenze des zweiten Körperdrittels reichend. Schwimmplättchen ziemlich dicht stehend, 20 an der Zahl. 1)ie Meridionalgefisse sind von gleicher Lïnge wie die Rippen. Mlagen gross, voluminis, Trichtergefiss kurz, schlank, in der Mitte leicht erweitert. Der Lintritt der adradialen in die Meridionalgefïsse liegt schräg ïber dem Trichter, im oberen Drittel der Rippen. Auf gleicher Höhe liegt 
die weite Oeffnung der kurzen, sehr weiten, am oralen Ende stumpf abgestutzten Scheiden, die nicht länger wie die Hälfte des Magens sind. Die Tentakelbasen sind klein, und gegen den Magen zu concav gekrümmt, diesem dicht angelagert. Der einzige, ganz erhaltene Tentakel zeigt an seinem Ende einen grösseren, blattförmigen Anhang; im uibrigen entbehrt er der Seitenfäden, während zwei Exemplare an den, in den Scheiden iibrig gebliebenen Tentakelstummeln fadenförmige Nebenfiden hatten, was aber, wie friher gezeigt, nicht von principieller Bedeutung ist. Geschlechtsreif.

Im Nagen befinden sich zwei lange, bis zur Hälfte desselben herabreichende Krausen, die wohl als Leber bezeichnet werden können. Sie liegen unter den Tentakelbasen und jede besteht aus einem grösseren mittleren, und zwei kleineren, seitlichen, verästelten Erhebungen des Magenepithels, dessen Zellen ein drüsiges Aussehen gewinnen. In jede dieser drei Abtheilungen entsendet das betreffende Magengefäss einen kleinen Zweig, der wie eine Rinne von oben nach unten in der Falte verläuft. Tentakelbasen, Nund und Leber zeigten eine gelbliche Färbung.

Eine Larve von $4 \mathrm{~mm}$. darf wohl hierher gerechnet werden, wofür nicht nur der Fundort spricht, sondern auch der ganze Habitus, die kurzen, concaven Tentakelbasen, der lange Magen, die Einmündungsstelle der adradialen in die Meridionalgefässe, wodurch sie den ausgewachsenen Exemplaren von Hormiphora sibogae sehr gleicht. Dass die Form der Larve eine mehr kugelige wie cylindrische, die Rippen noch kurz sind - diese Beobachtung wird an den meisten Larven gemacht, und findet ferner durch die Thatsache Bestätigung, dass bei einer cylindrischen Form die ältesten Exemplare am gestrecktesten sind - so sind hier die Exemplare von $7 \mathrm{~mm}$. weniger cylindrisch gestreckt, wie jene von $13 \mathrm{~mm}$. und stehen daher in der Mitte zwischen der Larve von $4 \mathrm{~mm}$. und den grössten Exemplaren.

Hormiphora sibogac unterscheidet sich von den übrigen Hormiphoren durch die kleinen, concav zum Magen gekrummten Tentakelbasen, die kurzen, am aboralen Ende stumpf abgestutzten, sehr weiten Scheiden, die weiten Scheidenöffnungen und die grosse Leber. Des weiteren unterscheidet sie sich von Hormiphora palmata und spatulata durch die Kürze der Rippen und Meridionalgefässe, von ersterer, sowie von Hormiphora plumosa und ochracca, durch die schräg über dem Trichter liegende Eintrittstelle der adradialen in die Meridionalgefässe, und von Hormiphora fusiformis durch die breiten Rippen.

Indo-Malayisch.

Gruppe b) Meridionalgefässe bis zum Munde reichend.

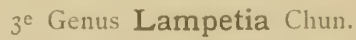

Lampetic Chun, Fauna u. Flora d. Golfs v. Neapel. p. $2 \$_{3}$, ISSO.

Bekannt sind bis jetzt nur zwei Arten, da die ron MIYER beschriebene Lampatia fusiformis cine Ilormiphora ist; die eine wurde von Quorr und Ganmind IS 33 entdeckt, ist aber zu ungeniggend beschricben und abgebildet um ein Wiedererkennen wahrscheinlich zu 
machen. Die Andere wurde von Cirux im Golf von Neapel gefunden und ron ihm Lampelia pancorina genannt. Auf seine Beschreibung derselben stützten sich bis jetzt die Gattungsmerkmale der Lampetien. Der Siboga-Expedition ist es gelungen, eine Ctenophore zu fangen, die durch ihre entschiedené Aehnlichkeit mit der Crusx'schen Lampetia, in die gleiche Gattung wie diese gebracht werden muss, um so mehr, als sie sich stark von allen iibrigen Cydippen unterscheidet. Der Vergleich dieser zwei Lampetien ermöglichte es, die gemeinsamen I'unkte, welche sie von den übrigen Ctenophoren trennen, hervorzuheben, und auszuscheiden was nur Speciesmerkmal ist. Die Grattungsmerkmale sind folgende:

Rippen kurz, das orale Körperdrittel nicht erreichend. Tentakelbasen sehr klein, auf der oralen Grenze des Rippenfeldes gelegen. Tentakelaustritt in der Nähe der Tentakelbasen, in der oralen Körperhälfte. Magen sehr weit und lang. Mund stark erweiterungsfähig. Perradiale Hauptstämme senkrecht neben dem Magen abwärts steigend.

*I. Lampetia pancerina Chun.

Lampetia pancerina Chun, Fauna u. Flora d. Golfs v. Neapel. p. $2 \$_{3}$, I8So.

$20-50 \mathrm{~mm}$

Körper cylindrisch, am aboralen Pol abgerundet. Mund sehr erweiterungsfähig. Rippen mit zahlreichen Schwimmplättchen, beginnen in der Nähe des Sinnespols und erreichen nicht das orale Körperdrittel. Meridionalgefässe den Mundrand erreichend. Magen sehr weit und sehr lang, das aborale Körperviertel überschreitend, gegen den Trichter verschmälert. Trichtergefäss ganz kurz, gegen den Sinnespol verjüngt. Perradiale Hauptstämme steigen senkrecht neben dem Magen oralwärts und gabeln sich dichotom, etwa in der Körpermitte. Tentakelbasis sehr klein, unterhalb der Gabeltheilung der perradialen Gefässe; Scheide sehr klein; Scheidenöffnung in gleicher Höhe mit der Mitte der Tentakelbasis. Fangfäden lang mit Nebenfiden.

Wenig durchsichtig; Farbe zart milchweiss, mit rosa Anflug. F’angfiden zart rosa pigmentirt. Mittelmeer.

2. Lampetia elegans nov. spec. Taf. I, Fig. 7 .

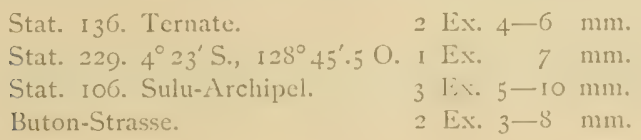

4-IO mm.

Körper cylindrisch, am aboralen Pol abgerundet. Mlund sehr weit, ähnlich dem von Lampetia pancerina, so dass er wohl wie dieser zum Kriechen verwendet werden kann. Rippen mit wenigen, grossen, weit von einander stehenden Schwimmplättchen von merkwirdig dreieckiger Form. Ihre Zahl betrug nur I ; die W'impern waren nicht mehr kenntlich. Die Rippen beginnen nahe am Sinnespol und reichen nicht bis zum unteren Körperdrittel, die Mleridionalgefisse aber bis zum Mundrand. Magen sehr weit und lang, bis nahe zum tiefeingesenkten Sinneskörper reichend - nicht verjügt am aboralen Theil. Trichtergefiss sehr kurz. Perradialgefisse steigen 
senkrecht neben dem Magen abwärts und liessen sich nur bis zur oralen Rippengrenze verfolgen. Tentakelbasis ein kleiner Nucleus, unter der Körpermitte goelegen. Leider waren alle Exemplare. in Spiritus conservirt und dadurch schlecht erhalten, so dass über Lage der Scheidenöffnung, Gabelung der verschiedenen Gefässe, und Histologie der Schwimmplättchen kein Aufschluss erhalten werden konnte.

Von Lampetia pancerina unterscheidet sich Lampotia clegans durch den, am aboralen Ende nicht verjüngten Magen, und durch die geringe Zahl und merkwürdige Form der Schwimmplättchen. Indo-Malayisch.

3. Lampetia clongata Quoiy und Gaimard.

Beroï clongatus Quoy und Gaimard, Zooph. V 4. p. 37, 1833. Ianira Quoiyi Lesson, p. I03, $1 \$_{43}$.

Guinea Strom.

$4^{\mathrm{e}}$ Genus Euplokamiș Chun.

Euplokanis Chun, Fauna u. Flora d. Golfs v. Neapel. p. 283 , i 880.

Da nur eine Art bekannt ist, können die Gattungsmerkmale noch nicht angegeben werden.

*. Euplokamis Stationis Chun.

Körper walzenförmig. Rippen und Meridionalgefässe nahe am Sinnespol beginnend und beide bis zum Mundrand reichend. Magen von mittlerer Grösse. Tentakelbasis klein, schräg gestellt, auf gleicher Höhe mit dem Trichter. Etwas über diesem, an der Grenze des aboralen Körperdrittels, die Scheidenöffnung. Scheide klein. Tentakel mit Nebenfäden, welche kräftige, stark gestreifte Muskulatur haben.

Einige schlecht erhaltene Exemplare konnten nicht mit Sicherheit bestimmt werden und zwar von

Stat. 40. Paternoster-Inseln. 3 Ex. 6-10 mm. vielleicht eine Hormiphora (?)

Stat. 96. Sulu-Archipel. 2 Ex. 7 u. 9 mm. vielleicht Hormiphora sibogae (?)

IIc Ordnung: LOBATAE Eschsch., L. Agassiz.

Beroüdac lobatac Eschscholtz, Isis. 1825, p. $74 \mathrm{I}$.

Mucmiidae Eschscholtz, Syst. d. Akal. p. 29, is29.

Callianiridac Mertens, Mém. Acad. St. Pétersb. 1833, p. 495.

Callymniidac Gegenbaur, Arch f. Nat. p. 192, 1856 .

Lobatae L. Agassiz, Contrib. Nat. Hist. U. St. Vol. III, p. 199 u. 289, I860.

Lobatae A. Agassiz, III. Cat. N" II, p. I4, I865.

Lobatac Chun, Fauna u. Flora d. Golfs v. Neapel. S. 287 , $18 S 0$. 
Körper in der Trichterebene comprimirt; Magenachse länger als die Trichterachse. Zwei mehr oder minder mächtige Lappen in der Magenebene. An den Enden der subtentakularen Rippen befinden sich 4 mit Schwimmplättchen versehene Aurikel. Die subventralen Rippen länger und tiefer entspringend als die subtentakularen. Mundöffnung weit. Die vier interradialen Gefaisse entspringen direkt aus dem Trichter. Die Meridionalgefïsse communiciren mit den Magengefässschenkeln und bilden auf den Lappen arabeskenähnliche Windungen. Tentakelbasis am oralen Pol. Scheide fehlt. Seitententakel liegen in, bis zum Ursprung der Aurikel reichenden Tentakelrinnen. Aeusserst zarte Geschöpfe.

Die Jugendformen sind Mertensien, welche bei der Eucharis geschlechtsreif wercien und sich fortpflanzen.

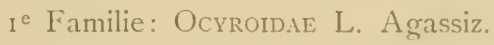

Ocyroidae Chun, Fauna u. Flaura d. Golfs v. Neapel p. 290, 1880.

Lappen fast selbständig vom Körper abgesetzt, von enormer Länge. Bei ihrer Ruhelage verlaufen sämmtliche Rippen horizontal in der Nagenebene, und zwar einander parallel, was bei den andern Lobatae nirgends der Fall ist und die sonst recht schwere Unterscheidung schnell ermöglicht. Aurikel von mittlerer Grösse, bandförmig und auf der Unterseite des Lappenursprungs liegend.

\section{Genus Ocyroe Rang.}

Ocyroe Rang, 1828. Nem. Soc. Hist. Nat. Paris V. 4, p. 170.

Von RANG wurden zuerst die bis jetzt allein bekannten drei Arten beschrieben.

I. Ocyroe fusca Rang.

Ocy'roe brane Rang, Mém. Soc. Hist. Nat. Paris V 4. p. 172, 1828 .

Ocyroe fusca Lesson, Hist. nat. d. Zooph. Akal. p. 99, 1843.

Seit RANG nicht wieder aufgefunden. Unterscheidet sich von den andern durch ihre bräunliche Färbung.

Kap Verdische-Inseln.

2. Ocyroc crystallina Rang.

Ocyroe crystallina Rang, Mćm. Soc. Hist. Nat. Paris V, 4. p. I72, 1828.

Ocyroe crystallina Lesson, Hist. nat. d. Zooph. Akal. p. 99, 1843.

Ocyroe crystallina Fewkes, Notes on Akal. fr. Tortugas. Bull. MIus. Comp. Zool. Cambridge V, 9. p. $251,1882$.

Ocyroe crystallina A. G. Mayer Some medusae from the Tortugas Florida, Bull. MIus. Comp. Zool. Harvard Coll. Vol. 37. N" 2. p. 81, 1900.

Beschreibungen und Abbildungen von RAxG sind zu summarisch um viel aus denselben SIBOGA-EXPEDITIE XII. 
schliessen zu können. Von MAYER liegt eine gute Abbildung vor, der leider jede Beschreibung fehlt. Nach Raxg soll Ocyroc crystallina kleiner sein wie Ocyroc maculata - sie entbehrt der fir letztere karakteristischen Flecken; ihre Lappen scheinen abgerundet zu sein.

Golfstrom.

3. Ocyroc maculata Rang.

Ocyroe tachée Rang, Mem. Soc. Hist. Nat. Paris. Vol. 4, p. 173, 1828.

Calymina Trevirani Mertens, Mém. Acad. St. Pétersb. 6 Ser. Vol. 2, p. 508, $1 \Omega_{33}$.

Ocyroe maculata Lesson, Hist. nat. d. Zooph. Akal. Paris. p. 19, I\$43.

Ocyroe maculata A. Agassiz, Illustr. Catal. Mus. Comp. Zool. Harward. Coll. N. II, p. 25, rS65.

Ocyroe maculata Fewkes, Report on the Acal. Bull. Mus. Comp. Zool. Cambridge. Vol. S. P. I 37, I 881 .

Ocyroe cry'stallina Fewkes, Notes on Akal. fr. Tortugas. Bull. Mus. Comp. Zool. Cambridge. Vol. 9, I882, p. 2SI.

Aus neuerer Zeit liegt nur die kurze Beschreibung von Fewkes vor, da Agassiz sie bloss citirt. Diese Beschreibung, sowie die vier Abbildungen sind nicht nach dem lebenden Thier, sondern nur nach Zeichnungen und Notizen von Agassiz angefertigt. Eine Differentialdiagnose fehlt, wie überhaupt stets bei Fewkes und Maxer. Das Haupterkennungsmerkmal der Ocyroc maculata besteht in clen vier grossen, dunklen Flecken auf der Unterseite der Loben. Fewkes hielt diese erst für entstanden durch eine Verstärkung der in den Loben befindlichen Muskelfibrillen, während er in einer späteren Publikation ỉber Ocy'roe cry'stallina zu dem Schluss kommt, dass es richtige Pigmentflecken sind. Fewkes findet eine allgemeine Aehnlichkeit mit Bolina, nur dass die Loben grösser, spitzer, die Aurikel länger sind. Ein weit besseres Merkmal, das als Gattungsmerkmal dienen kann, liegt in dem, mit der Magenebene und unter einander parallelen Verlauf aller Rippen, von denen die kurzen subtentakularen am oralen Ende gegen einander $s$ förmig eingekrümmt sind.

Der Unterschied von Ocyroe crystallina, der (nach Vergleich mit der MAYER'schen Zeich. nung letzterer) in dem Mangel an "wartlike protuberances upon the surface" an dem oralen Theil der Meridionalgefässe besteht, rührt sicher nur von einer Unvollständigkeit der Zeichnung von FEwhes her, denn ich habe sie an conservirten Exemplaren von Ocyroc maculata ebenfalls gesehen. Bei genauer Untersuchung zeigte sich, dass es baumförmige, blindendende Seitenästchen der Meridionalgefässe sind, die mit dem Alter immer dichter werden und schliesslich wie eine dichte, aus parallelen, dicken Strichen gebildete Streifung aussehen, welche über den Meridionalgelüssen verläuft in dem Theil, der sich auf den Lappen befindet.

Antillen, St. Vincent, Guineastrom.

4. Larve von Ocyroc(?).

Ocyroe cry'stallina Fewkes, Notes on Akal. fr. Tortugas Bull. Mus. Comp. Zool. Cambridge. Vol. 9, 1882, p. $25 \mathrm{I}$.

Fewkes beschreibt als Larven einer Ocyroc crystallina eine Larve von der er selbst sagt, dass sie eben so gut eine solche von Ocyroe maculosa oder fusca sein könnte. 
Unter dem Material der Siboga-Expedition fanden sich 24 Exemplare der gleichen Art Ocy'roc und zwar in

$\begin{array}{lrrr}\text { Stat. 53. } & \text { I0 Ex. } & 5-24 \mathrm{~mm} . \\ \text { Stat. 194-197. I Ex. } & \text { I } 3 \mathrm{~mm} . \\ \text { Stat. I36. } & \text { I3 Ex. } & 20-50 \mathrm{~mm} .\end{array}$

Zu welcher Species sie gehören, lässt sich nicht entscheiden, ehe bessere Unterscheidungsmerkmale zwischen den drei bekannten Ocyroc-Species angegeben werden, denn die von RaxG hervorgehobenen Unterschiede in der Grösse haben keinen praktischen Wert. Der einzige, bis jetzt angefuihrte Unterschied beruht auf der Firbung - auf der braunen Farbe bei Ocyroc fusca, auf dem Mangel an Farbe bei Ocyroc crystallina, auf den vier dunklen Pigmentflecken bei Ocyroc maculata. Diese Unterschiede verschwinden aber bei Formol und Spirituskonservirung so vollständig, wie jede andere Färbung und damit ist die Möglichkeit der Species Bestimmung verloren.

IIIe Ordnung: BEROÏDAE Eschscholtz.

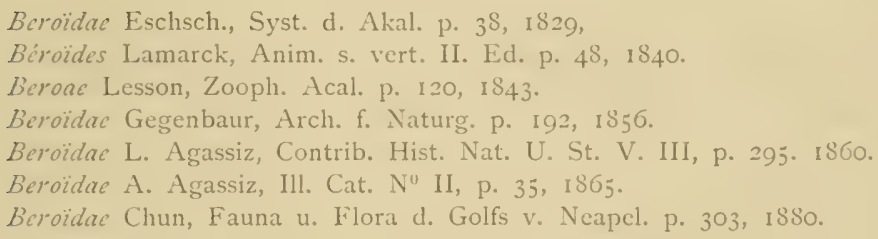

In der Trichterebene abgeplattete Rippenquallen von conischer, eiförmiger oder tiaraähnlicher Form. Mund weit, Magen voluminös. Der Sinneskörper liegt frei; der Polplattenrand crhebt sich zu verästelten Zöttchen. Die Tentakelgefässe und der Tentakelapparat fehlen. Der Anfangsteil des Magens ist mit săbelförmigen Cilien besetzt. Die Magenwülste und der unpare Theil des Trichtergefisses fehlen. Die Meridionalgefisse je einer vorderen und hinteren Körperhälfte treten mit den Magengefässschenkeln am Mundrand in Communication und treiben allseitig Prolifikationen, welche die Gallerte durchsetzen oder zu einem peripheren Maschenwerke zusammentreten. So sind die Gefässsysteme zweier Körperhälften getrennt.

Crrus fand nur bei Jugendstadien Lïngenunterschiede in den Rippen, wihihend AGissiz sie noch bei der ausgewachsenen Bcrö̈ cucumis feststellte. Der Zwischenraum zwischen den subventralen Rippen ist stets der geringste.

An dem vollständigen Fehlen eines Tentakelapparates erkennt man sofort jede Beroïde. Der weite Mund und Magen, die Zöttchen des Polplattenrandes und der, aus zwei Hiilften bestehende, ringförmige Kanal, in den Meridional- und Magengefisse minden, lassen keinen Zweifel aufkommen, ob man es mit der Ordnung der Beroïdae zu thun hat. Schwerer festzustellen hingegen sind die Species Merkmale, was teilweise auf friherer, ungenigender Beobachtung und Beschreibung beruht, so dass unter den verschiedensten Namen die gleichen Arten beschrieben wurden. Es ist das grosse Verdienst Cinux's, dem die Systematik der Ctenophoren so vieles 
verdankt, die umfangreiche Litteratur über Beroïdae durchgearbeitet und die, unter den verschiedensten Namen beschriebenen gleichen Species zusammen gestellt zu haben, wodurch ihre Zahl sehr reducirt wurde. $\mathrm{Ob}$ er recht hat, sie alle einer einzigen Gattung unterzuordnen, kann fraglich erscheinen, um so mehr, als bei den ibrigen Ordnungen oft sehr geringe Unterschiede, so bei Hormiphora und Plcurobrachia, zur Aufstellung von selbständigen Gattungen verwendet wurden. Es liegt hierin eine gewisse Inconsequenz, die wohl mit der Zeit, wenn ein umfangreicheres Vergleichsmaterial vorliegt, beseitigt werden wird.

Die ron L. Agsssiz aufgestellten Unterfamilien der Neisidae und Rangidae stiutzen sich, wie Chux mit Recht bemerkt, auf viel zu ungenügend bekannte Vertreter, als dass sie den übrigen Beroën entgegengestellt werden dürften.

\section{Ic Gattung Beroë Browne.}

Berö Browne, the Civil and nat. Hist. of Jamaica. p. 394, I756.

Beroë Fabricius, Fauna Groenland. p. 361, 1780.

Idyia Fréminville, nouv. Bull. Soc. Philomat. p. 329, ISog.

Beroi

Medea Eschscholtz, Syst. d. Akal. p. 35, I\$29.

Pandora

Idya Mertens, Mém. Ac. St. Pétersb. p. 532, I 833 .

Berö̈ Delle Chiaje, Mlém. anim. senza vert. T. III, p. 56, I 828 .

Berö̈ Delle Chiaje, Anim. s. vert. T. IV, p. IOS, I 84 I.

Niis

Beraë

Idlid

Medea

Lesson, Zooph. Acal. p. 67, i 843 .

Pandora

Cydalisia

Idyia L. Agassiz, Contr. Nat. Hist. U. S. V. III, p. 270 , I860.

Idjia A. Agassiz, Ill. Cat. $\mathrm{N}^{0}$ II, p. 35, I865.

Idyopsis A. Agassiz, Ill. Cat. No II, $\mathrm{IS}_{5}$.

Idjopsis L. Agassiz, Contr. Nat. Hist. U. S. V. III, I 860.

Berö̈ Chun, Fauna u. Flora d. Golfs v. Neapel p. 306, isSo.

". Borö ovata Eschscholtz.

Beroë Patrick Browne, Civ. \& nat. Hist. Jan. p. 384, 1756.

Beroë albens Forskâl, Descr. anim. p. III, I775.

Beroï ovata lischscholtz, Syst. d. Ak. p. 36,1829 .

Berö̈ capensis

Berö̈ punctata Chamisso et Eysenhardt, N. Act. Acad. L. Car. T. X, p. 360, 1821. Bcroë ovala

Beroë punctata Eschscholtz, Syst. d. Ak. p. 37.

Beroi ozatus Delle Chiaje, Mem. Anim. s. vert. p. 58, iS2S.

Beroi ovatus Delle Chiaje, Anim. invert. p. 109, I84I.

Idya mertcnsii Brandt, Mém. Acad. St. Pétersb. p. 536, 1833 .

Berö̈ forskiulii Milne Edwards, Ann. Sc. nat. IIe Sér. T. XVI, P. 207, I\$41.

Bcroö ovatus Spagnolini, Atti. Soc. Ital. Sc. nat. Vol, XI, Fasc. III, 1868.

beroc̈ allens Panceri, Atti. R. Accad. Nap. Vol. V, p. 2, 1872. 
Berö oialns Eimer, Zool. Studien auf Capri I. Beroe ovatus is 73 .

Berö ovata Chun, Fauna u. Flora d. Golfs v. Neapel. p. 30S, isSo.

Berö oratus Bosc, Hist. Nat. d. vers. (Suite ì IBufton 64) kl. O. T. II, P. I49, 1802.

Beroï gilva Eschscholtz, Syst. d. Akal. p. 37, 1829.

Idyia oïata Lesson, Zoopl. Acal. p. I34, 1843 .

Idjiopsis clarlizi

Idyiopsis affinis $\mid$ L. Agassiz, Contr. Nat. Hist. U. St. V. III, p. 2SS, 296, IS60.

Beroi ointa Fewkes, Notes on Ak. fr. the Tortugas. Bull. Mus. Comp. Zool. Cambridge V S, p. 251,1882 .

Berö̈ oiata Chun, d. Ctenoph. d. Plankton-Exped. p. 26, isgs.

I $60 \mathrm{~mm}$.

Nach der Cruv'schen Beschreibung ist der Körper langgestreckt, cylindrisch, wenig abgeplattet, gegen den aboralen Pol allmählich in halbkreisförmigem Bogen verjünt. Lippen schmal, wenig vorgezogen. Ein Hauptunterscheidungsmerkmal ist, dass die Prolificationen der Meridionalgefässe kein anastomosirendes Netzwerk unter sich bilden, sondern sich baumförmig unter der Körperoberfläche in der Gallerte verästeln und blind enden. Einzelne Ausläufer treten gegen die Magenwand und stellen dorten ein mit den Stolonen der Magengefässe communicirendes, weitmaschiges Netzwerk her. Geschlechtsprodukte in der ganzen Länge der Meridionalgefässe, in deren seitlichen WVandungen, nicht in follikelähnlichen Auftreibungen vorspringend. Rippen fast bis zum Munde reichend, von gleicher Länge.

Berö̈ ovata recapitulirt in ihren Larven das, für Berö̈ cucumis typische Verhalten, in sofern die Magengefässe dann noch keine Anastomosen mit den, auf den Magen iibertretenden Prolificationen der Meridionalgefässe eingehen.

Mediterran-atlantisch.

*2. Berö̈ cucamis Fabricius.

Beroë cucumis Fabricius, Fauna Groenlandica. p. 361, 17\$o.

Berö̈ cucumis Eschscholtz, Syst. d. Akal. p. 36, i\$29.

Berö̈ cucumis M. Sars, Beskriv. og Jagttag. over nogle maerkel. eller nye i Havet ect. p. 301 , Bergen 1835 .

Idyia borealis

Medea fulgens $\}$ Lesson, Hist. nat. d. Zooph. Acal. p. 136. Paris IS43.

Medea arctica

Idyia roseolx L. Agassiz, Contrib. Nat. Hist. U. St. V. III, I. II, p. 270, 296, 1860.

Idjia roseola A. Agassiz, North. Am. Acal. Ill. Catal. Mus. Comp. Zool. Harvard Coll. 1I, p. 36. Idyia cucamis A. Agassiz, North. Am. Acal. III. Catal. Mus. Comp. Zool. Harvard Coll. II, p. 36,1865 .

Idyia cucumis Levinsen. Vidensk Meddel. Naturh. Foren. p. 7. Kjöbenhavn ISg2.

Berö̈ cucumis Vanhöffen, d. Grönl. Cten. Bibl. Zool. H. 20, P. 20. IS95.

Beroë cucumis Chun, d. 13eziehg. zm. arkt. u. antarkt Plancton. 1897.

Berö̈ cucumis Chun, d. Cten d. Plankton-Exped. 1). 22, ISgs.

Berö̈ cucumis gleicht so sehr Borö̈ ovata, dass eine Unterscheidung of fast unmogglich ist. Der einzige Unterschied von Letzterer ist, nach CuUw, dass die auf die Magenwand ijbertretenden Prolificationen der Meridionalgefässe sich nicht in Verbindung mit dem Magrengefiss setzen, sondern blind enden.

Arktisch. Kiisten der Verein. Staaten, Ost- und Nordsee. 
$\mathrm{Ob}$ das eine, von der Siboga-Expedition gebrachte. Exemplar von

Stat. 144. Nördlich von der Insel Damar. I Ex. $7 \mathrm{~cm}$.

Bcrö̈ ovata oder cucumis ist, konnte nicht festgestellt werden, da diese Anastomosenhildung zwischen Meridional und Magengefissen bei einem lange conservirten und geschrumpften Thiere, ausser auf Microtom-Schnitten nicht zu erkennen ist, und dieses Exemplar geschont werden sollte.

3. Beroë forskilii Chun. Taf. II, Fig. 4-7. Taf. IV, Fig. 7 .

Berö̈ rufescens Forskâl, Descr. anim. p. I I I, 1775.

Cydalisia mitraeformis Lesson, Voy. Coqu. Zool. Zooph. Acal. p. I38.

Idja penicillata Mertens, Mém. Acad. St. Pétersb. p. 534, I\$33.

Beroë forskïlii Milne Edwards, Ann. Sc. nat. Ile Sér. T. XVI, p. 207, I84r.

Berö̈ rufescens Will, Horae Terg. p. 20.

Beroë mfescenș Spagnolini, Atti. Ser. Ital. Sc. nat. Vol. XI, Fasc. III, I868.

Beroë rufescens I'anceri, Atti. R. Accad. Nap. Vol. V, p. 2, I872.

Berö̈ forslïlii Chun, Fauna u. Flora d. Golfs v. Neapel. p. 309, 1880.

Berö̈ australis Mayer, Acal. fr. Fiji. Isl. Bull. Mus. Comp. Zool. Harvard Coll. Vol. XXXII,

N. 9, p. 177 .

Stat. 168. Nördlich v. d. Insel Sabuda. 7 Ex. I,5-5 mm.

Stat. 99. $6^{\circ} 7^{\prime} .5 \mathrm{~N}$., $120^{\circ} 26^{\prime} \mathrm{O}$. 2 Ex. I 5 u. $20 \mathrm{~mm}$.

Stat. 194-197. $1^{\circ} 53^{\prime} \cdot 5$ S., $126^{\circ} 39^{\prime}$ O. I4 Ex. $3-37 \mathrm{~mm}$.

$\mathrm{I}, 5-40 \mathrm{~mm}$.

Stark abgeplattet, vom Mund, mit den dicken, halbkreisförmig geschwungenen Lippen, konisch verjüngt; der aborale Pol scharf zugespitzt. Die Rippen von gleicher Länge, bis fast zum Munde reichend. Prolificationen der Meridionalgefässe bilden, unter der Körperoberfläche sowohl, wie auf der Magenwand, ein engmaschiges Netzwerk. Nur sehr wenig Stolonen durchsetzen quer die Gallerte. Geschlechtsprodukte in follikelartigen, seitlichen Ausstuilpungen der Meridionalgefässe; ihre Bildung am oralen Ende der Rippen sistirt.

Berö̈ australis Mayer scheint, nach der Abbildung, mit Bcrö̈ forskälii Chun identisch zu sein. Dies sicher festzustellen ist nicht möglich, nach der flüchtigen, einer Differentialdiagnose ganz entbehrenden Beschreibung, die kaum etwas anderes erwähnt, als was für jede Beroïde und teilweise für alle Ctenophoren gilt, z.B. dass S Wimperreihen vorhanden sind, unter welchen \& Radialkanäle verlaufen, dass das Thier mit Hilfe der Wimperreihen schwimmen kann, und der Rand der Polplatte sich in Zöttchen erhebt!

Eine Anzahl junger Larven von $1-6 \mathrm{~mm}$. zeigten schon die cylindrische Form der Burö̈ forskilii mit dem kleinen Mund. Bei einer Larven von $3 \mathrm{~mm}$. hatten die Rippen, die von gleicher Länge waren, kaum die Grenze des oberen Körperdrittels erreicht. Der Abstand zwischen den einzelnen Rippen war der gleiche. Die bis zum Mundrand reichenden Meridionalgrefässe entsandten nach beiden Seiten eine Anzahl Seitengefässe. Diese endeten noch blind bei einer Larven von $3 \mathrm{~mm}$., während sich bei einer Larven von $6 \mathrm{~mm}$. schon einzelne Anastomosen gebildet hatten. Am Magengefïss waren noch gar keine Seitengefaisse kenntlich.

Inclo-Malayisch, Australien. 
4. Berö pandora (Eschscholtz). Taf. II, Fig. S und 9. Taf. III, Fig. 9 und ro.

Pandora flemingii Eschscholtz, Syst. d. Akal. p. 39, 1829.

Stat. $215^{2}$. Bei der Inscl Kabia.

Stat. 205. Lohio-Bay, Buton-Strasse.

Stat. 172. Zwischen Gisser u. Ceram-Laut. I Ex.

Stat. 250. Westseite 1. Insel Taam. $7 \mathrm{~mm}$.

Stat. 243. $4^{\circ} 30^{\prime} .2$ S., $129^{\circ} 25^{\prime}, \quad 3 \mathrm{~mm}$.

Stat. 225. Bei den Lucipara-Inseln. I Ex. $10 \mathrm{~mm}$.

Stat. 144. Nördlich d. Insel Damar. I Ex. $13 \mathrm{~mm}$.

Stat, I65. Ostküste v. Misool. 2 Ex. 15 u. $25 \mathrm{~mm}$.

6 -25 mm..

Diese Bcrö̈ wurde zuerst aus dem nördlichen stillen Ocean, östlich von Japan, von Escischoltz beschrieben und seitdem nicht wieder gefunden. Ich kann Cuuv nicht beistimmen wenn er schreibt, dass sie ganz ungenügend karakterisirt sei. Die Escuscnoltz'sche Abbildung giebt das Wesentliche und seine Beschreibung ist eine, im Vergleich zu denjenigen mancher neuerer Forscher recht gute und bezeichnende, die, trotz aller Küirze, das Wichtigste und spezifisch Eigenthümliche hervorhebt. Es kann keinem Zweifel unterliegen, dass die, von der SibogaExpedition gefundenen Exemplare mit der Pandora flemingii Eschscholtz identisch sind. Allerdings hat sie Eschscholtz zu einer besonderen Gattung gemacht, welche Cuux, wie alle übrigen Gattungen der Berö̈dae, zur einzigen Gattung Berö̈ vereinigte. Escrischoltz zu Ehren mag der Name Pandora erhalten bleiben.

Die Form lässt sich am besten mit einem Theewärmer vergleichen (Teacozy): kugelig, mit stark verküzter Verticalaxe, nicht ganz so hoch wie lang; stark abgeplattet in der Trichterebene und gegen den stumpfen, aboralen Pol nur wenig verjüngt; die Mundöffnung, wie schon Eschscholtz angiebt, gerade abgeschnitten und der lippenlose Mund mit einem schmalen einwairts geschlagenen Rand. Die Rippen sind sehr kurz, von ungleicher Länge und zwar erreichen die längeren, auf den Schmalseiten des Körpers gelegenen, subventralen Rippen kaum das orale Körperdrittel, die kürzeren, auf der Breitseite des Körpers befindlichen, subtentacularen kaum die Hälfte. Die Rippen sind einander parweise genähert, und zwar am meisten die subventralen, die einen fast parallelen Verlauf haben. Die von Esciscroutz als spezifische Eigenthimlichkeit der Pandora hervorgehobene Tatsache, dass die Rippen in Furchen liegen, die vollständig iiber den Schwimmplatten geschlossen werden können, ist, nach HErTwig, allen Berö̈den eigen. Die Schwimmplättchen stehen dicht bei einander; ihre Wimpern sind ziemlich kurz und grehen in einem dichten Büschel ab. Die Meridional- und Magengefisse reichen bis zum Mundrand und senden Seitenzweige ab, die teils unter sich anastomosiren, teils blind enden. Die Kürperwand ist sehr dün (Folge vielleicht der Conservirung), so dass Magen- und Meridionalgefisse fast in einer Ebene liegen und ein besonderes Oberllichen- und Magengefissnetz nicht unterschieden werden konnte. Nur die, dem Magengefäss zugekehrten Seitenäste der subtentacularen Meridionalgefässe anastomosiren mit dem ersteren, während die Seitenäste der ibbrigen Meridionalgefässe allein unter sich anastomosiren.

Die jüngsten Formen von 6 und $7 \mathrm{~mm}$. zeigten eine fast kugrelige Gestalt, mit mehr 
oder weniger stark eingeschlagenem Mundrand; bei einem Exemplar von $15 \mathrm{~mm}$. hatten die lïngeren subventralen Rippen noch nicht die Körpermitte erreicht.

Ḱeines der Exemplare war geschlechtsreif. Die Farbe war eine blass gelb-grünliche, während Eschscioltz eine weissgelbliche Farbe mit blass rötlich braunen Gefässen angibt.

Als spezifische Merkmale der Berö̈ pandora können die merkwürdige Gestalt, die sehr kurze Verticalaxe, die kurzen, ungleich langen Rippen, und der Mangel eines eigenen Magengefissnetzes gelten.

$\mathrm{Ob}$ Pandora floningii mit Recht, oder vielmehr Consequenz, als eigene Gattung von Ciuvy gestrichen wurde, möchte ich bezweifeln. Sie ist, wie schon Agassiz i 860 sagt, die einzige, bis jetzt bekannte Beroë welche im ausgewachsenem Zustand ganz kurze Rippen, von deutlich ungleicher Länge, hat, während bei allen übrigen ausgewachsenen Beroën die Rippen von gleicher Länge sind und bis fast zum Nunde reichen.

Indo-Malayisch, östlich von Japan.

5. Berö̈ pandorina nov. spec. Taf. III, Fig. I-8. Taf. IV, Fig. 4-6.

Stat. I36. Ternate.

Stat, $215^{4}$. Bei der Insel Kabia.

5 Ex. $2-4 \mathrm{~mm}$.

2-6 $\mathrm{mm}$.

Unter dem Material der Siboga-Expedition befinden sich eine Anzahl merkwürdiger, larvenartiger Beroën, von denen die grössten Exemplare fast wie Medusen aussehen. Bei allen ist der sehr weite Nund von einem Kranz langer und starker Cilien umgeben.

Die jüngste Larve von $2 \mathrm{~mm}$. hat die Form eines Hutes mit schmaler Krämpe, um deren äusserstem Rand eine, aus langen, dicken Cilien gebildete Wimperschnur läuft. Die Mundöfnung war ausserordentlich weit, die Rippen paarweise angeordnet, sehr kurz und zwar erreichten die längeren, subventralen kaum die Körpermitte. Während ein ziemlicher Raum die subtentacularen trennte, in welchem man die Magengefässe durch die Gallerte schimmern sah, waren die subventralen stark genähert und verliefen einander fast parallel. Die zwei Hälften der Polplatten ragten als halbkugelige Erhebungen über die Oberfläche, zwischen diesen eine Spalte lassend, die zum Sinneskörper führte. Auf Schnitten zeigte sich nun die merkwürdige Thatsache, dass diese Larve vollständig umgestülpt war so, dass die Rippen und Wimperplatten nach innen, in den Pseudomagen ragten, während der Cilienbesatz des Magens sich auf der nunmehrigen Körperoberfläche befand. Letzterer überschreitet die Grenze des oralen Körperdrittels und sind die Cilien alle von ausserordentlicher Dicke und Starrheit, wie die um den Mund befindlichen. Dass diese Umkehrung erst auf den Schnitten erkannt wurde, liegt daran, dass, da die Larve nicht geschlechtsreif, die Gefässe sehr eng waren und auf Durchsichtsbildern überhaupt nicht kenntlich. Dadurch schimmerten die Rippen durch die Gallerte, den Eindruck machend, dass sie in diese zurückgezogen waren.

Die nächste Larve von $2,3 \mathrm{~mm}$, nicht umgestiilpt, war gestreckter, mehr cylindrisch, die Mundöffnung weniger weit. Die Rippen erreichten noch nicht die Körpermitte, während der innere Cilienbesatz sie schon tiberschritten hatte. Auch diese Larve war nicht geschlechtsreif. 
Die bis zum Munde reichenden Meridionalgefisse waren kenntlich, aber nur oralwirts von den Rippen.

Die dritte Larve von $4 \mathrm{~mm}$, glich mehr der ersteren, durch ihre hutfürmige Gestalt und den sehr weiten Mund. Der aborale Pol war eingesenkt und vom Mund aus sichtbar; auch sie war, wie die erste Larve, umgestiilpt; bei ihr aber sah man deutlich die oberfichlich verlaufenden Meridionalgefisse in ihrer ganzen Länge, während die Rippen unter diesen durchschimmerten; die längeren, einander stark genäherten und fast parallel verlaufenden subventralen hatten jetzt die Körpermitte überschritten. Diese Larve war geschlechtsreif und daher, im Gegensatz zu den beiden ersten Larven, auf Durchsichtspriiparaten dic stark erweiterten und mit Geschlechtsprodukten angefuillten Meridionalgefisse so gut sichtbar. Am Mundrand befand sich ebenfalls der, mit blossem Auge wahrnehmbare Krranz langer, dicker Cilien.

Die grössten Larven von 4,5 und $6 \mathrm{~mm}$. sahen fast aus wie Medusen, mit flachgewölbtem Schirm und breitem, nach aussen gebreitetem Velum. Ueber der flachen Kuppel der grösseren, aboralen Kö̈perhälfte liefen die Rippen, von denen die längeren, subventralen den oralen Rand nicht ganz erreichten. Unter ihr folgte die breite Krimpe mit dem Cilienbesatz. Der Mund war ausserordentlich gross; die Unterseite hatte die Form einer flachen Schale, welche nur gegen die Mitte zu eine grössere Vertiefung zeigte, die der Kuppelwölbung entsprach. Von diesen Larven waren beide geschlechtsreif und die eine umgestiulpt.

Fassen wir das Karakteristische dieser Larven zusammen: die kurze, bei den iltesten Exemplaren ausserordentlich kurze Verticalaxe, die bei Letzteren um mehr wie die Hälfte hinter der Längenaxe zurückbleibt; die grosse Weite des Mundes, welche die vollständige Umstülpung sehr erleichtert; der auffallige Wimperbesatz um den Mund, der sich in den Magen bis iiber seine Längenhälfte fortsetzt; die ungleiche Länge der kurzen Rippen, von denen die subventralen einander stark genähert sind und fast parallel verlaufen. Nun fragt es sich — haben wir es hier tatsächlich mit Larven zu thun und dann von welchen Beroën - oder aber mit einer neuen, eigentümlichen Form von Beroë?

Anfangs schien die Vermuthung naheliegend, dass es Larven der Berö̈ pandora wäiren; 1) fanden sich in gleichen Gläsern jüngere und ältere Exemplare der fraglichen Larven zusammen mit ganz jungen Exemplaren von Bcrö̈ pandora, 2) wenn auch keine direkten Uebergangsformen von der einen zur anderen vorlagen, so zeigten doch die altesten Exemplare der Ersteren grosse Aehnlichkeit in vielen Punkten mit den jüngsten der Letzteren : bei beiden die auffallende Annäherung der fast parallel verlaufenden subventralen Rippen, der grosse Zwischenraum zwischen den subtentacularen; bei beiden die Rippen kïrzer wie bei allen iibrigen Beroën: dabei der paarweise Unterschied in deren Länge, sodass die subventralen die längeren sind, wenn auch der Längenunterschied bei der jüngsten borö̈ pandora ein geringerer ist, was auf das Alter zurückgeführt werden muss. Bei beiden die kugelige Form, das gerade abgestutzte orale Ende. Gegen die Zusammengehörigkeit beider formen scheint bei bcrö̈ pandorina der sehr weite Mund zu sprechen, dessen breiter Saum vom Körper absteht, während er bei Jiroc̈ pandora eingeschlagen ist, ferner und vor allem aber die histologische Struktur des Cilienbesatzes am Nund und im Magen. Dieser Cilienbesatz um den Mund und im Magen von Bscrö̈ pandorina hat eine histologische Struktur ganz eigener. Art, die ich bei keiner der iibrigen Beroiden, auch 
nirgends erwähnt, fand. Bei Bcrö̈ pandora sind, wie bei Berö̈ forskalii, die ich daraufhin untersuchte, die Cilien fein und zart, nur etwas länger und wenig schmäler wie die zugehörigen Cylinderzellen, deren Kerne sehr gross sind. Bei Berö̈ pandorina hingegen sind die Cilien ausserordentlich dick, starr und lang, so dass der von ihnen gebildete, breite Saum mit blossem Auge gut sichtbar ist. Die Länge ist ungefähr die vierfache der zugehörigen Cylinderzelle, die doppelte der Cilien bei Berö̈ pandora, während sie ungefähr vier Mal so dick sind wie bei Letzterer. Die Zellen sind fast ron gleicher Grösse bei beiden, aber bei Berö̈ pandorina schief zur Oberfläche gerichtet, so dass die senkrecht zur Oberfläche gestellten Cilien eine Knickung erfahren, bei ihrem Abgang von der Zelle, zu welcher sie dann in einem fast rechten Winkel stehen; auch sind die Kerne sehr klein, verglichen mit denen von Berö̈ pandora. Eine weitere Eigentümlichkeit besteht in dem Vorhandensein einer Art Schaltzellen, die sich teils zwischen zwei Zellen, resp. zwei Cilien befinden, teils direkt an den Cilien selbst; in letzterem Fall können sie mehr oder weniger an diesen in die Höhe greifen, wo sie dann hauptsächlich durch ihre Kerne kenntlich sind. Ob diese Schaltzellen junge, in Entwicklung begriffene Zellen sind, die sich erst später zu einer Cylinderzelle mit Cilienfortsatz entwickeln - das konnte nicht festgestellt werden. Bei Bcrö̈ pandora fanden sie sich nicht, ebenso wenig bei Beroü forskalii. Auch fanden sich nirgends Uebergänge von einem Cilienbesatz zum anderen, was am meisten dagegen zu sprechen scheint, dass Berö̈ pandorina ein Larven-Stadium von Berö̈ pandora sei. Ferner muss berïcksichtigt werden, dass Berö̈ pandorina geschlechtsreif ist - von Berö̈ Pandora war kein einziges Exemplar geschlechtsreif. Nun könnte man annehmen, dass, wenn beide Formen zusammengehören, Dissogonic, wie sie CHux bei Eucharis nachgewiesen hat, vorliegt so, dass sowohl die Larve geschlechtsreif wird, wie auch später wieder das ausgewachsene Thier.

Bis weitere Funde und Untersuchungen vorliegen, kann bezüglich der Stellung der Bcrö̈ pandorina nichts bestimmtes ausgesagt werden und ich habe ihr einstweilen den Species-Namen pandorina gegeben, durch den die, in vielen Punkten auffallende Aehnlichkeit mit Berö pandora angedeutet werden soll. Wenn es sich später herausstellt, dass Berö pandorina tatsächlich eine eigene Species ist, dann könnte man sie mit Bcrö̈ pandora zu einer eigenen Gattung, der von Escischoltz aufgestellten Gattung Pandora machen, die als Unterscheidungsmerkmale hätte:

Kugelig, bis flach-schirmartig, sehr weiter Mund mit nach innen oder nach aussen geschlagenem Mundrand; die kurzen, die Körperhälfte kaum iberschreitenden Rippen von ungleicher Länge, die längeren subventralen Rippen einander stark genähert und fast parallel verlaufend.

Neue Funde dieser interessanten Beroïden werden hoffentlich bald gemacht und die Frage dann entschieden werden.

Einige unkenntliche Ctenophorenreste fanden sich in:

Stat. 146. Nördlich der östlichen Widi-Gruppe.

Stat. I86. $3^{\circ} 10^{\prime} .5$ S., $127^{\circ} 20^{\prime} .5 \mathrm{O}$.

Stat. 168. Nördlich d. Sabuda-Inseln. 


\title{
SCHLUSS.
}

Ueberblicken wir das, von der Siboga-Expedition gesammelte Ctenophoren-Material, so muss die Ausbeute, in anbetracht der Schwierigkeiten des Fangens und Conservierens, eine recht befriedigende genannt werden. Zehn Species liegen vor:

\author{
Pleurobrachia globosa nov. spec. \\ Pleurobrachia pigmentata nov. spec. \\ Hormiphora ochracea (Mayer). \\ Hormiphora sibogae nov. spec. \\ Lampetia clegans nov. spec. \\ Beroë ovata oder cucumis. \\ Beroö forskilii Chun. \\ Bcrö̈ pandora (Eschscholtz). \\ Borö̈ pandorina nov. spec. (?) \\ Ocyroe crystallina oder maculata.
}

Von diesen ro Species sind 5 neu und die eine, Berö̈ pandora ist seit Eschscioltz, 1 S29, zum ersten Mal wieder gefunden worden.

Sie rühren alle von der Oberfäche her, und befindet sich keine einzige Tiefseeform darunter; dies war übrigens kaum anders zu erwarten, sind doch bis jetzt Tiefsecformen noch gänzlich unbekannt, was wohl auf die Schwierigkeit des Fangens zuriickgefihhrt werden muss, nicht aber auf ein vollständiges Fehlen derselben, wie Crun wohl mit Recht bemerkt.

Wirft man einen Blick auf die geographische Verbreitung der bis jetzt bekannten Ctenophoren so zeigt es sich, dass Funde aus dem Malayischen Archipel, resp. aus dem Indischen Ocean noch gänzlich fehlten und ist es ein Verdienst der Siboga-Expedition, weitere Aufschlüsse über das Verbreitungsgebiet der Ctenophoren und ihrer einzelnen Gattungen gebracht zu haben.

Von den drei bisher bekannten Pleurobrachien stammen, wenn man von den ganz alten Arten, der Beroë (Fanira) cucumis Mertens aus dem nördlichen stillen Ocean und der Pleurobrachie (Bcrö̈) basteri Lesson der peruanischen Kiste absieht, die cine, Pluurobrachia pilcus aus dem arktischen Stromgebiet, zwei, Plcurobrachia rhodopis und Plourobrachia bachci 
aus dem Atlantischen Ocean. Hiezu gesellen sich jetzt zwei Arten aus dem Indo-Malayischen Archipel, Plearobrachia globosa und Plaurobrachia pigmentuta. Dieser Fund zeigt, dass das Verbreitungsgebiet der Pleurobrachien ein viel grösseres ist, wie bisher angenommen wurde und macht es wahrscheinlich, dass auch im pacifischen Ocean Pleurobrachien vorkommen.

Die Gattung Hormiphora war, im Atlantischen Ocean, durch drei Arten vertreten und zwar durch Hormiphora plumosa, palmata und spatulata, im tropisch pacifischen Ocean durch 2 Arten, Hormiphora fusiformis (Mayer) und Hormiphora ochracca (Mayer). Von letzterer brachte die Siboga-Expedition, aus dem Indo-Malayischen Archipel, einige Exemplare, was nicht so merkwürdig ist, da doch beide Meere in breiter Verbindung mit einander stehen; und ferner eine neue Art, die Hormiphora sibogac.

Die bis jetzt allein bekannten zwei Lampetien, Lampetia clongata Quoy \& Gaimard und Lampetia pancerini Chun sind atlantische Formen. Zu ihnen kommt jetzt Lampetia clegans aus dem Malayischen Archipel.

Von Beroïden ist Berö̈ cucumis atlantisch, Bcrö̈ ovata mediterran, während Berö̈ forskilii sowohl im stillen, wie im atlantischen Ocean ausserordentlich verbreitet ist. Letztere kommt auch im Malayischen Archipel vor, ebenso die, bisher nur durch einen einzigen Fund aus dem tropischen stillen Ocean, östlich von Japan, bekannte Berö̈ pandora, und die neue Species Beroë pandorina.

Weit verbreitet im tropischen atlantischen Ocean sind die drei von RANG beschriebenen Ocyroen, Ocyroc crystallina, Ocyroc maculata und Ocyroe fusca. Auch im Malayischen Archipel fanden sich eine ziemliche Anzahl Ocyroe, ob sie aber der ersten oder der zweiten Species angehören, liess sich nicht bestimmen. 
BESTIMIIUNGSTABELLE

FÜR DIE:

PLEUROBRACHIADAE UND BEROÏDAE. 
Familie :

Körper im Querschnitt meist rund; Rippen von gleicher Länge;

\section{Gruppe $a$ ).}

Meridionalgefässe $n$ icht bis $z$ um Munde reich

Tentakelbasis schräg, zwischen Magen und Körperoberfläche.

Pleurobrachia Flemming.

Eifórmig Rippen lang. Scheide und Tentakelbasis ziemlich lang. Eintritt $\mathrm{A}, \mathrm{G}$, steil uiber dem Trichter im aboralen drittel der Rippe. Dariber die ścheideaöffnung.

7'lanobrachia pilcus Fabricius.
Eifurmig, Rippen zicmlich kurz. Scheide kurz. Tentakelbas is nicht lang, Eintritt A.G. auf gleicher Höhe mit dem Trichter, in der Mlitte der Rippe, auf gleicher Höhe die scheidenöffnung.

Pleurobrachia rhodopis Chun.
Eiformig, ähnlich Kugelig, kurzer Magen, Pleurobrachia pileus. Eintritt A.G. Über der Scheidenöff$\mathrm{nung}$. die aborale Magengrenze nicht erreichend, Scheide klein. Tentakelbasis rundlich, klein. Eintritt A.G.schräg über dem Trichter, im oralen drittel d. Rippe. Scheidenöf $\mathrm{nung}$ an d. aboralen Grenze des Rippenfeldes.

\section{Plewrobrachia} bachei Agassiz. Rippen sehr kurz,

Cylindrisch, das untere Ǩörperdrittel wie eine Krause Rippen lang, breit, mit Pigmentstreifen in den Wimperplatten. Tentakelbasis lang, sehr tief oral gelegen.

\section{Pleurobrachic} globosa nov. spec.
Eiförmig, oral stark verjünt. $\mathrm{R}$ i p pen schmal, ziemlich lang. Meridionalgefässe ebenso lang. Eintritt A.G. auf gleicher Höhe wie der Trichter, aboral von d. Rippenmitte. Scheide voluminös. Tentakelbasis lang, d. Magen dicht angelagert.

\section{Hormipliora} flumosa Chun.
Cylindrisch, an beiden l'olen verjüngt. Rippen breit, lang. M eridionalgefïsse etwas länger. Eintritt A.G. schräg über $d$. Trichter, nahe am aboralen Rippenende. Scheide voluminös. Tentakelbasis dem Magen nicht dicht angelagert, oral divergirend.

Hormiphora spatulafi Chưn.

ANMERKUnG: Eintritt $\mathbf{A}, \mathrm{G} .=$ Eintritt der adradialen in die Meridionalgefässe.

Ordnung :

In der Trichterebene mehr oder weniger a Rand der Polplatten in Zöttchen. Meridi

Körper coniscla verjuingt, stark abgeplattet. Sinnes. pol spitz. Lippen dick, $1 / 2$ kreisförmig geschwungen. Rippen fast bis zum Munde reichend, von gleicher Länge, Geschlechtsprodukte in follikelähnlichen Auftreibungen der Gefísse. Anastomosirendes Netzwerk auf Magen- und Kürperwand, durch Prolificationen von Meridional- und Magengefissen gebildet.
Körper cylindrisch, wenig abgeplattet. Sinnespol ab kippen fast bis zum Munde reichend, von gleicher Linge. nicht in follikelähnlichen Auftreibungen der Gefässe sonderu anastomosirendes Netzwerk auf der Körperwand, durch P'rolifica

Anastomosen auf der Nagenwand zwischen den Stolonen der Magen- und Meridionalgefisse.

Keine Ana wand zwischen Meridionalgefis: 
Chun.

en; keine flügelförmigen Fortsätze am oralen oder aboralen Pol.

\section{Gruppe b).}

Meridionalgefässe bis zum Munde reichend.

Magen dicht angelagert.

L. Ag.

Sehr langgestreckt indrisch, oraler Pol ggezogen verjüingt. p pen schmal, nlich lang. Mi e rion a l gefässe asolang. Eintritt *. schrig uber dem chter. Scheide

lank, zierlich gewungen. Tenta$1 \mathrm{~b}$ as is lang, dem gen dicht ange. miegt.

Hormiphore siformis (Mayer).
Cylindrisch, an beiden Polen veriüngt. Rippen kurz. Meridionalgefässe bedeutend lïnger. E in tritt A.G. auf gleicher Höhe mit d. Trichter. Scheide sehr lang. Tentakelbas is sehr lang, dem Magen dicht angelagert.

Hormiphora ocliracea (Mayer).
Rippen nicht bis zum Nunde

reichend; letzterer sehr erweiterungsfähig.

\section{Lampetia Chun.}

Eiförmig, oral wenis verjüngt. Ki $\mathrm{p} p$ e breit, ziemlich lang. Meridionalgefässe gleich lang. E intritt $A$. G. schrïg über dem Trichter. Scheidc voluminös, kurz, oral abgestutzt. T entakelbasis klein, concar gegen den Magen.

Hormiphora sibogac nov. spec. pancirint Chun.
Rippen bis zum Nunde reichend; letzterer wenig crweiterungsfälig

Euplokamis Chun.

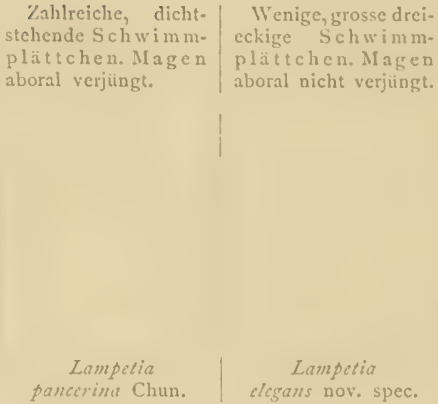

Walzenförmig. Tentakelbas is klcin.
Euplokamis stationis Chun.

ischoltz.

apparat fehlend. Mund und Magen weit. isse in das orale Ringgefäss mündend.

Körper kugelfömig, stark abgeplattet. Sinnespol rund; oraler l'ol gerade abgeschnitten. If und mit breit eingeschlagenem Kand. I, i p pen schmal. Rippen kurz, von ungleicher Länge, die subtentacularen, längeren Kippen einander stark genahert und fast parallel verlaufend. Stolonen von Meridional- und Magengefissen unter einander anastomosirend.
Körper tlach hutfurmig, wenig abgeplattet. Sinnespol rund; oraler l'ol gerade abgeschnitten. If und sehr weit, mit ziemlich breit nach aussen geschlagenem Rand, mit cinem Kranz langer dicker Cilien, kippen kurz, yon ungleicher länge; dic subtentacularen, langeren Rippen einander stark genahert und fast parallel verlaufend. Oft umgestiilpt. 



\section{LITTERATUR-VERZEICHNISS.}

Agassiz, L. Contrib. to nat. hist. of Acal. N. Amer. P. 2. On the Beroid Medusae of the shores of Massach. in their perfect state of devel. in: Mem. Am. Acad. N. S. V. 5, 1. 2, IS50.

Contrib. to nat. hist. Unit. St. V. 3. P. II. Ctenophorae, p. 153-301, 1860.

Agassiz, A. North Am. Acal. In I1I. Cat. Mus. Comp. Zool. Harvard Coll. N. Il, 1865.

Bosc, S. A. G. Hist. nat. d. Vers (Suite à Bufion 64). R1. O. Tome II, p. I-300. Paris ISO2.

Chanisso, A. et Eysenhardt. De anim. ect. In Nova Acta Acad. Cacs. Leopoldinae V. 10, p. II, p. $543-574,1 S_{2} \mathrm{I}$.

Delle Chiaje, Descrizioni e Natomia degli Animali Invertebrati della Sicilia Citeriore ect. Tome IV (Echinod. Acal. Polipi) Napoli, Is 4 r.

Ci.AUs, Bemerk. über Cten. u. Med. Zeitschr. f. wissensch. Zool. V, 14. p. 386 , iS64.

Chun, d. Cten. d. Golfes v. Neapel ect. Fauna u. Flora d. Golfes v. Neapel herausgeg. v. d. Zool. Stat. in Neapel. I Monogr. IS80, XVIII.

Bericht iber eine nach d. Kan. Inseln im WVinter $18 \$ 7 / 8 \delta$ ausgef. Reise. Sitz. Ber. Akad. Wiss. Berlin I $889, \mathrm{XXX}$.

d. Dissogonie. Festschr. f. Leuckart, I892.

d. Bez. zw. d. arkt. u. d. antarkt Planct. Stuttg. 1897.

d. Cten. d. Plankton-Exped. In Ergebn. d. Plankton-Exped. d. Humboldt-Stiftung. Kiel ISgS.

Delage, Traité de Zool. concrête. Coelentérés. Paris Igor.

Eschscholtz, Fk. Syst. d. Akal. Eine ausführl. Beschreib. aller medusenart. Strahlth. Berlin, I\$29.

FABRICIUS, Fauna Groenlandica Hafniae et Lipsiae, 1780 .

FEwres, I. W. Studies of the Jelly fishes of Naragansett Bay. Bull. Mus. Comp. Zool. Cambridge V 8 . I 881 .

Report on the Acalephac, ibid. V S, ISSI.

Notes on Acalephs fr. the Tortugas, with a descript. of New Genera and Species. Ibid. Vol 9. $\mathrm{N}^{0} 7,1882$.

On a few Medusac from the Bermudas. Bull. Mus. Comp. Zool. Harvard Coll. Vol. I I, No 3 , 1si:

On certain Medusac from New England. Bull. Mus. Comp. Zool. Harvard Coll. Vol. 13, $\mathbb{N}^{0} 7,1 \ldots \ldots$.

On a Collection of Med. Proc. U. S. Nat. Mus. Vol. S.

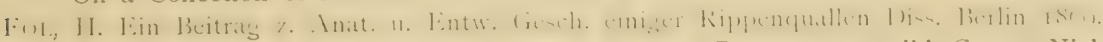

Forskil, P. Descript. Anim. Avium Amphib. Pisc. ect. Post mortem edid. Carsten Niebuhr Hauniac, 1775 .

- Icones Rer. Nat. dito Hauniae, 1776.

Gegendaur, Studien über Organisat. u. Syst. d. Cten. Arch. f. Naturgesch. 1856.

GRAEFFE. Thierfauna d. Golfes von Triest Arch. Zuol. Inst. Wien. 13d. 5. 1S84.

Harthaub, Q. Beitrige z. Mecresfauna v. Helgoland. IV. d. Coel. Helgolands. Wissensch. Meeresunters. Kommis. Kiel u. Biol Anst. Helgoland. N. F. V. I. is 94.

Hertwig, R. Ueber d. Bau d. Cten. Jen. \%citschr. f. Naturw. V. I4, isso.

I.ENDEXFEL1), V. Ueber Coclenteraten der Siclsec. Zeitschr. f. Wissensch. Zuologie. 13d. 41. 
LESSON, R. P. Zoophytes. Voyage autour du monde ect. publ. par L. I. Duperey. Zool. T. II. P. II, 2 Div. Paris, I\$26.

- Hist. nat. d. Zoophytes. Acal. Paris, 1843 .

Levinsen, G. Meduser, Ctenoph. og. Hydroider fra Gronlands Vestkyst, in: Vidensk. Meddel. Naturh. Foren. Kjöbenhavn, I892.

Matrens, Fr. Spitzbergische u. Grönländ. Reise-13eschr. Hamburg, I675.

Mertens, H. Beob. u. Unters. über d. Beroë-art. Akal. Mém. Acad. St. Petersb. 6 Ser. V. 2, 1833.

MAYer. Some Med. from the Tortugas Florida. Bull. Mus. Comp. Zool. Harvard. Coll. Vol. 37. No 2, rgoo.

- Description of New and Little Known Med. from the Western Atlant. Ibid. Vol. 37, N ${ }^{0}$ I, I900.

Acalephs from the Fiji Islands. Ibid. Vol. 32. $\mathrm{N}^{0}$ 9. I 899.

Medusae. Mém. Mus. Comp. Zool. Harvard. Coll. V. XXVI. No $3,1902$.

Quoy u. Gaimard, Voyage de découvertes de l'Astrolabe ect. Zool. T. IV. Zoophytes. Paris, I\$33.

RANG, M. Etablissement d. 1. fam. des Beroüdes ect. Mém. Soc. Hist. nat. Paris. V. 4. Paris, I828.

SARS, M. Beskriv. og Jagttag. over nogle maerkelige ect. Bergen, i $\$ 35$.

- Biidrag til Kundskaben om Middelhavets Littoral-Fauna, Reisebem. fra Italien. III Ctenoph. In Nyt. Magaz. far Naturvidensk. Bd. I0. Heft 1. Christiania, 1859.

VANIIÖFFEN, E. d. gröni. Cten. In Bibl. Zool. Heft 20. I895. 
TAFELN 


\section{TAFEL I.}

Fig. [-4. Plcurobrachia globosa nov. spec.

Fir. 1. Plaurabrachia globosa, $6 \mathrm{~mm}$. von der Trichterebene gesehen.

Fin. 2. Plaurobrachia globosa, $6 \mathrm{~mm}$. von der Magenebene gesehen.

Fin. 3. Plcurobrachia globosa, $6 \mathrm{~mm}$. vom oralen Pol gesehen.

Fig. 4. Larve von Plaurobrachia globosa, $2 \mathrm{~mm}$. von der Trichterebene gesehen.

Fig. 5 und 6. Pleurobrachia pigmentata nov. spec.

Fig. 5. Planrobrachia pigmontata, $5 \mathrm{~mm}$. von der Trichterebene aus.

Fig. 6. Pleurobrachia pigmentata, $5 \mathrm{~mm}$. von der Magenebene aus.

Fig. 7. Lampetia elegans, nov. spec. $7 \mathrm{~mm}$. 

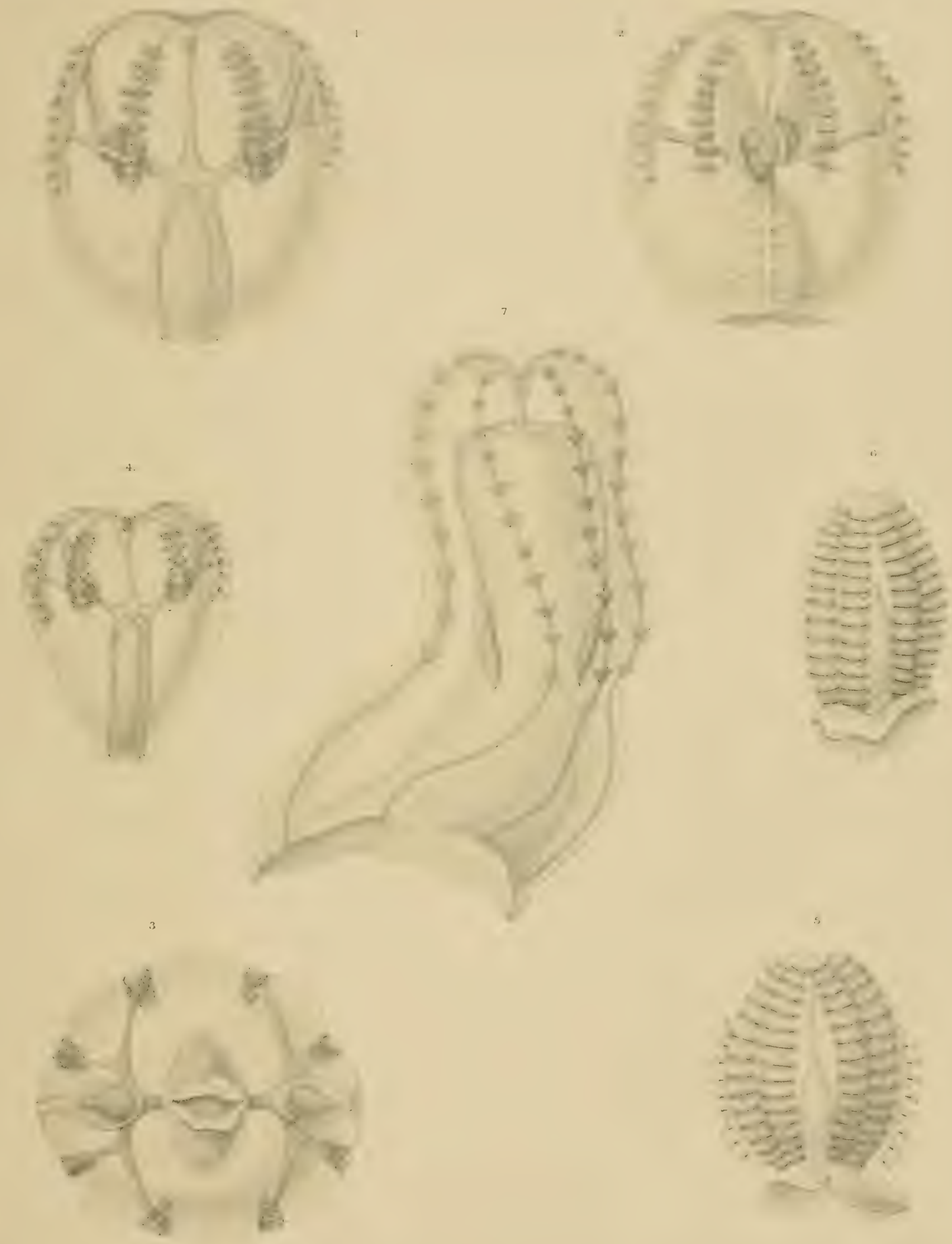



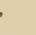




\section{TAFEL II.}

Fig. I-3. Hormiphora sibogae nov. spec.

Fig. 1. Hormiphora sibogae, $\mathrm{I}_{3} \mathrm{~mm}$. von der Magenebene gesehen.

Ïig. 2. Hormiphora sibogae, I $3 \mathrm{~mm}$. von der Trichterebene gesehen.

Fig. 3. Larve von Hormiphora sibogae, $4 \mathrm{~mm}$. von der Trichterebene gesehen.

Fig. 4-7. Berö̈ forskilii Chun.

I.is. 4. Larve von Bcrö̈ forskalii, $3 \mathrm{~mm}$. von der Magenebene gesehen. Fig. 5. Larve von Berö̈ forskalii, $6 \mathrm{~mm}$. von der Magenebene gesehen. Firg. 6. Larve von Beroë forskilii, I $\mathrm{mm}$. von der Magenebene gesehen. liis. 7. Larve von Berö̈ forskalii, I mm. vom aboralen Pol gesehen.

Fig. S und 9. Beroë pandora (Eschscholtz).

Iig. s. B'rö̈ pandora, I $2 \mathrm{~mm}$. vom aboralen Pol gesehen.

I:H. 1). Berö̈ pandora, I $2 \mathrm{~mm}$. von der Magenebene gesehen. 

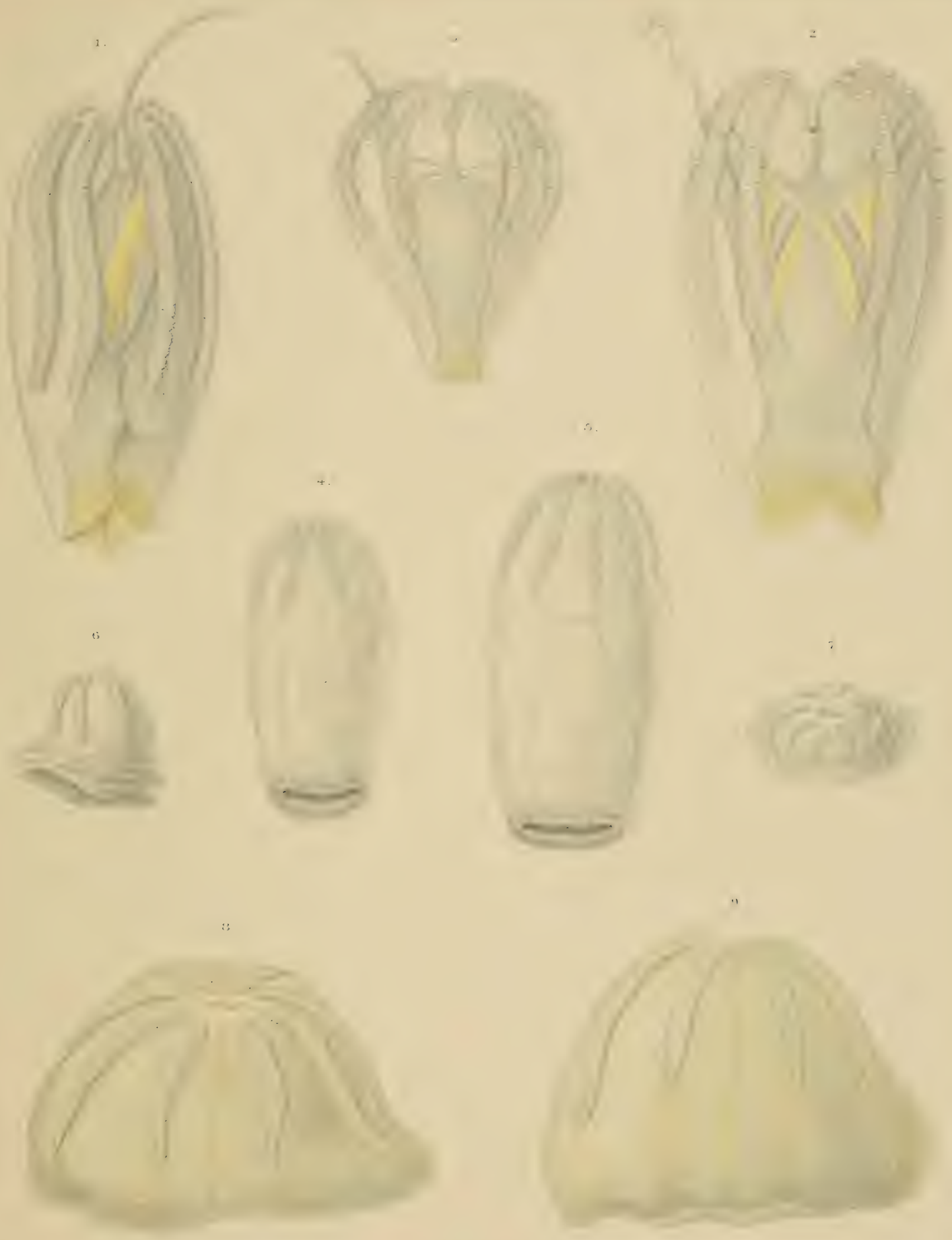



\section{TAFEL III.}

Beroë pandorina nov. spec.

Fig. 1. Bcrö̈ pandorina, $2.0 \mathrm{~mm}$. von der Trichterebene gesehen (umgestülpt).

Fig. 2. Berö̈ pandorina, $2,0 \mathrm{~mm}$. vom aboralen Pol gesehen.

Fig. 3. Berö̈ pandorina, $2,0 \mathrm{~mm}$. vom oralen Pol gesehen.

Fig. 4. Berö̈ pandorina, 2,3 mm. von der Magenebene gesehen.

Fig. 5. Berö̈ pandorina, $+\mathrm{mm}$. von der Magenebene gesehen (umgestülpt).

Fig. i). Berö̈ pandorina, $4 \mathrm{~mm}$, vom oralen Pol gesehen (aboraler Pol eingestülpt).

Fig. 7. Berö̈ pandorina, $6 \mathrm{~mm}$. vom oralen Pol gesehen (umgestuilpt).

Fig. \&. Bcrö̈ pandorina, $6 \mathrm{~mm}$. vom aboralen Pol gesehen (umgestulpt).

Fig. () und го. Berö̈ pandora (Eschscholtz).

lis. 9. Berö̈ pandora, $6 \mathrm{~mm}$. von der Magenebene gesehen.

I.im. 10. Berö̈ pandora, () mm. vom aboralen Pol gesehen. 


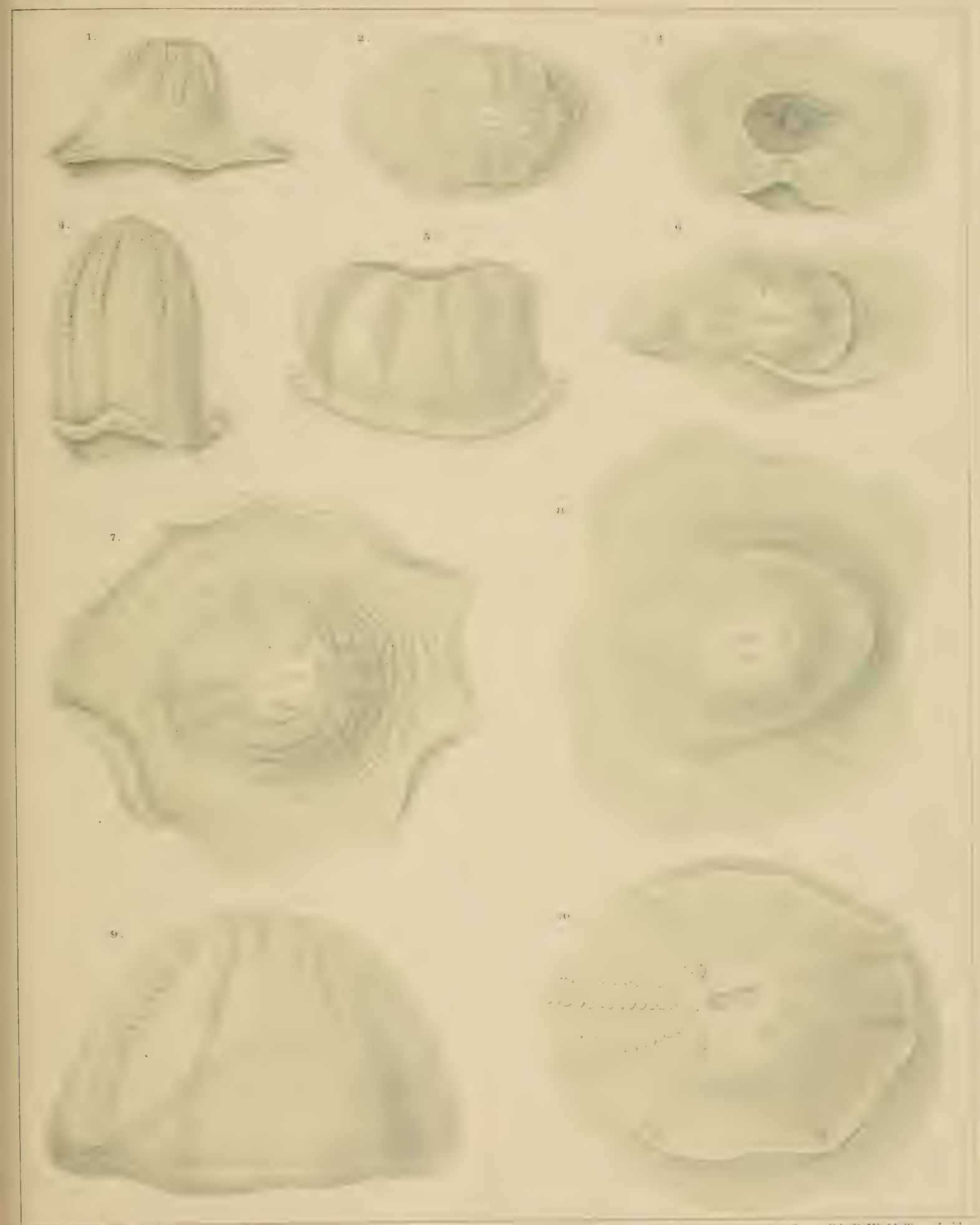






\section{TAFEL IV.}

Fig. r-3. Plenrobrachia pigmentata nov. spec.

Fig. I. Pleurobrachia pigmentata, $5 \mathrm{~mm}$. Querschnitt.

Iïr. 2. Pleurobrachia pigmentata, $5 \mathrm{~mm}$. Längsschnitt durch eine Rippe, so dass ein Wimperplättchen quer getroffen ist (Oel Immers.).

Iing. 3. Plearobrachia pigmentata, $5 \mathrm{~mm}$. Querschnitt durch eine Rippe, so dass ein Wimperplättchen längs getroffen ist (Oel Immers.) P.:= Pigment.

Fig. 4-6. Bcrö̈ pandorina nov. spec.

lïr. 4. Berö̈ pandorina, $2 \mathrm{~mm}$. Längsschnitt (umgestiilpt).

I“is. 5. Berö̈ pandorina, 2,3 mm. Längsschnitt.

lïg. 6. Borö̈ pandorina $2 \mathrm{~mm}$. Starre dicke Cilien um den Mundrand und im Magen (Oel Immers.). C. = Cilie, S.Z. = Schaltzelle, Cyl. Z. = Cylinder Zelle.

I.iv. 7. Berö̈ forskilii Chun, Wimperbesatz des Magens (Oel Immers.). 

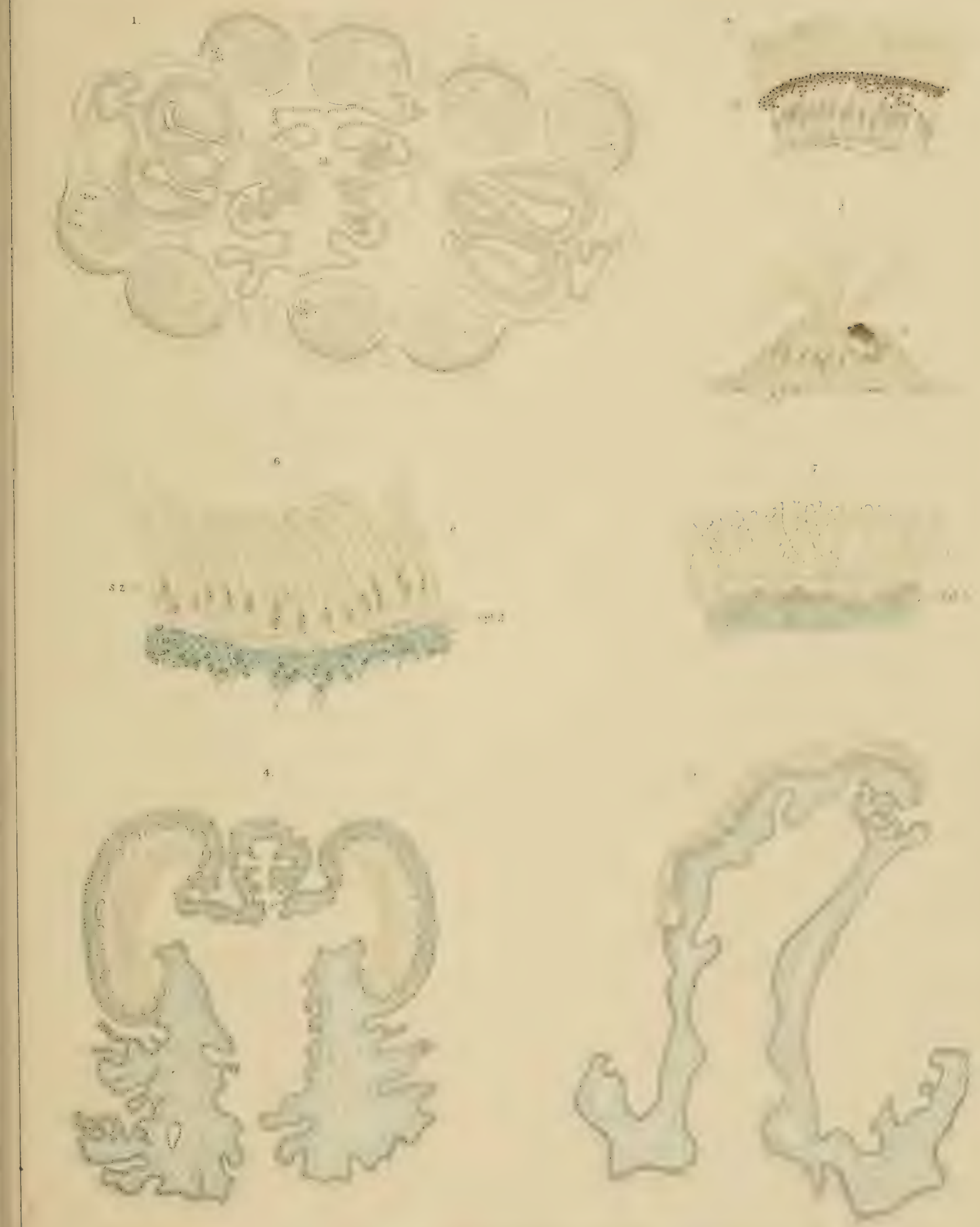

Fanny Mroer del. 




\section{CONDITIONS GÉNÉRALES DE VENTE.}

$1^{\circ}$. L'ouvrage du "Siboga" se composera d'une série de monographies.

$n^{2}$. Ces monographies paraitront au fur et à mesure qu'elles seront prêtes.

$3^{2}$. Le prix de chaque monographie sera différent, mais nous avons adopté comme base générale du prix de vente: pour une feuille d'impression sans fig. flor. 0.15; pour une feuille avec fig. flor. 0.20 à 0.25 ; pour une planche noire flor. 0.25 ; pour une planche coloriée flor. 0.40 ; pour une pliotogravure flor. 0.60 .

$4^{c}$. If y aura deux modes de souscription:

a. La souscription à l'ouvrage complet.

b. La souscription à des monographies séparées en nombre restreint.

Dans ce dernier cas, le prix des monographies sera majoré de $25 \%$.

$5^{\circ}$. L'ouvrage sera réuni en volumes avec titres et index. Les souscripteurs à l'ouvrage complet recevront ces titres et index, au fur et à mesure que chaque volume sera complet.

\section{$z=$ Déjà paru:}

IE Livratison. (Monegraphic XLIV) C. Ph. Sluiter. Die Holothurien dur Siboga-Expedition. Mit ro Tafuln. Pour les souscripteurs ì l'ouvrage complet. $\quad$ of 7.50 20 Livraison. (Monographie LX) E. S. Barton. The genus Halimeda. With 4 plates . . . . $f 2.40$ Pour les souscripteurs at l'ouvrage complet.

3" 1.ivraison. (Monographie I) Max Weber. Introduction et description de l'expedition. Avec Liste des Stations et 2 Cartes.......... . . . . . . . . . . . . . . . f 9. Pour les souscriptenirs à l'onvrage complet. $f 9.75$

f. Livraison. (Anonographic II) G. F. Tydeman. Description of the ship and appliances used for scientific exploration. With 3 plates and illustrations. . . . . . . . . . . f 2.50 Pour les souscripteurs à l'ouvrage complet., $2 .-$

5e I, ivaison. (Menographie XLVII) H. F. Nierstrasz. The Solenogastres of the Sibogat-Expedition. With six plates. ................ f 490 Pour les sonscriptenirs à l'ouvrage complet. $\begin{array}{r}7 \\ 3.90\end{array}$

C: Livraison. (Afonographie XIII) J. Versluys. 1)ie Gorgoniclen der Sibogat-Lxpedition.

I. Die Chrysogorgidac. . . . . . . . . . . . . . \& $f \cdot 3 \cdot 75$ Pour les souscriptcurs à l'ouvrage complet.

7 I.ivraisen. (Monographic XVIa) A. Alcock. Report on the Deep-Scal Matureporaria of the SibongaExpedition. With five plates. . . . . . . . . . . f 5575

Pour les souscripteurs à louvrage complet. $\quad 4.60$

Q. Liwrison. (Monomphie XXY) C. Ph. Sluiter. Die Sipunculiden und Echiuriden der Siboga-lixpedition. Mit vier Tafeln und drei Figuren im Text. . . . . . . . . . . . f 3.75 Pour les souscripleurs à louvrage complet. $n$ 3.-

9) Livraten. Mronegraphic VI) G. C. J. Vosmaer and J. H. Vernhout. The Porifera of the SibograExpedition. With five plates. . . . . . . . . . f $3-$. $^{\circ}$ Pour les sonscripteurs à louturage complet. $\quad$ o 2.40

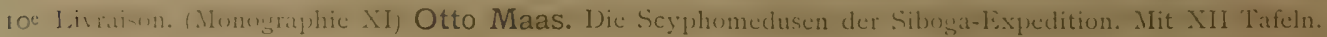

Pour les souscripteurs à l'ouvrage complet. $\begin{array}{r}f 9.50 \\ 77.50\end{array}$ 



$(20182)^{2}$

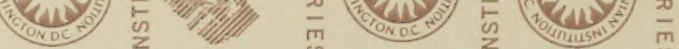

12)(111)

LIBRARIES SMITHSONIAN INSTITUTION NOIINLILSNI NVINOSHLIWS

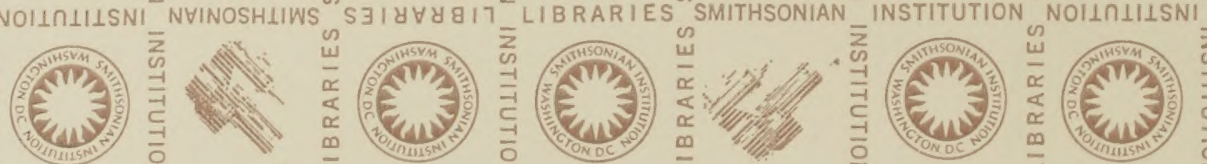

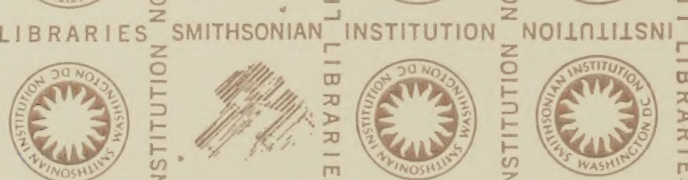

NOIINIIISNI

NVINOSHLIW

क

$\geqq$
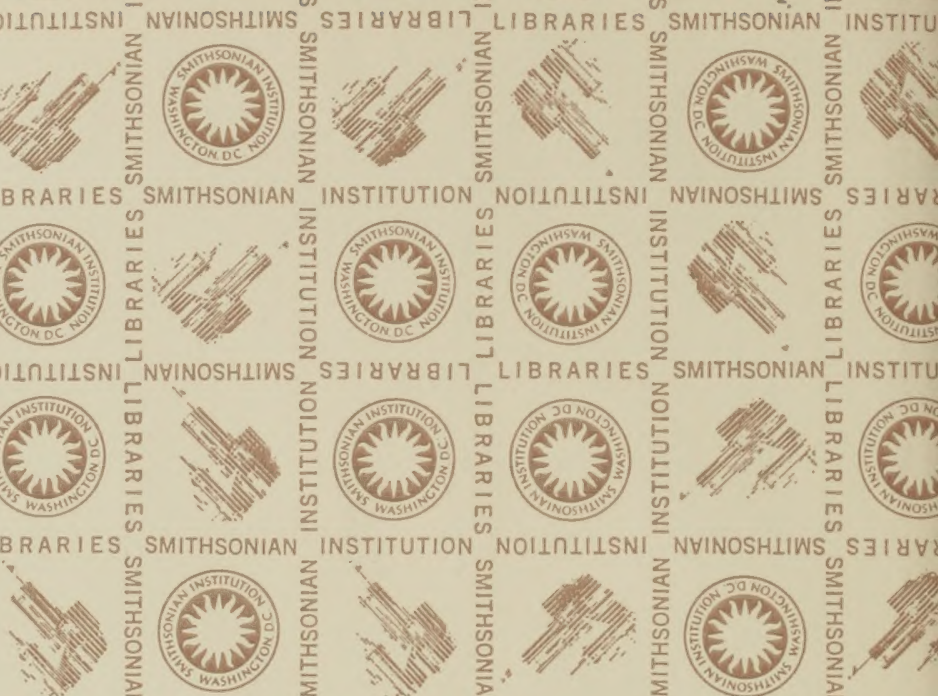

" SMITHSONIAN
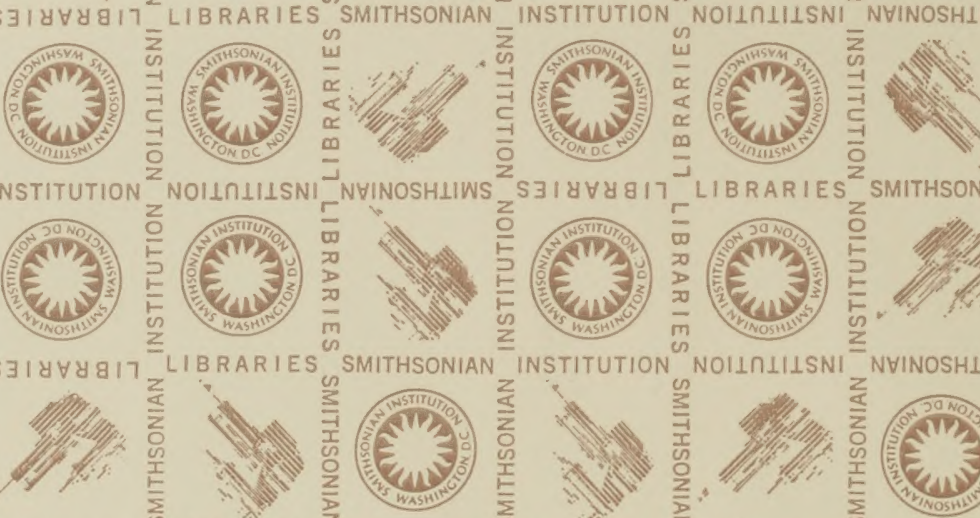

(1)

${ }_{\text {SMITHSONIAN INSTITU }}$

(ivi)

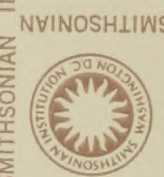

S $S \exists 14 \forall ?$
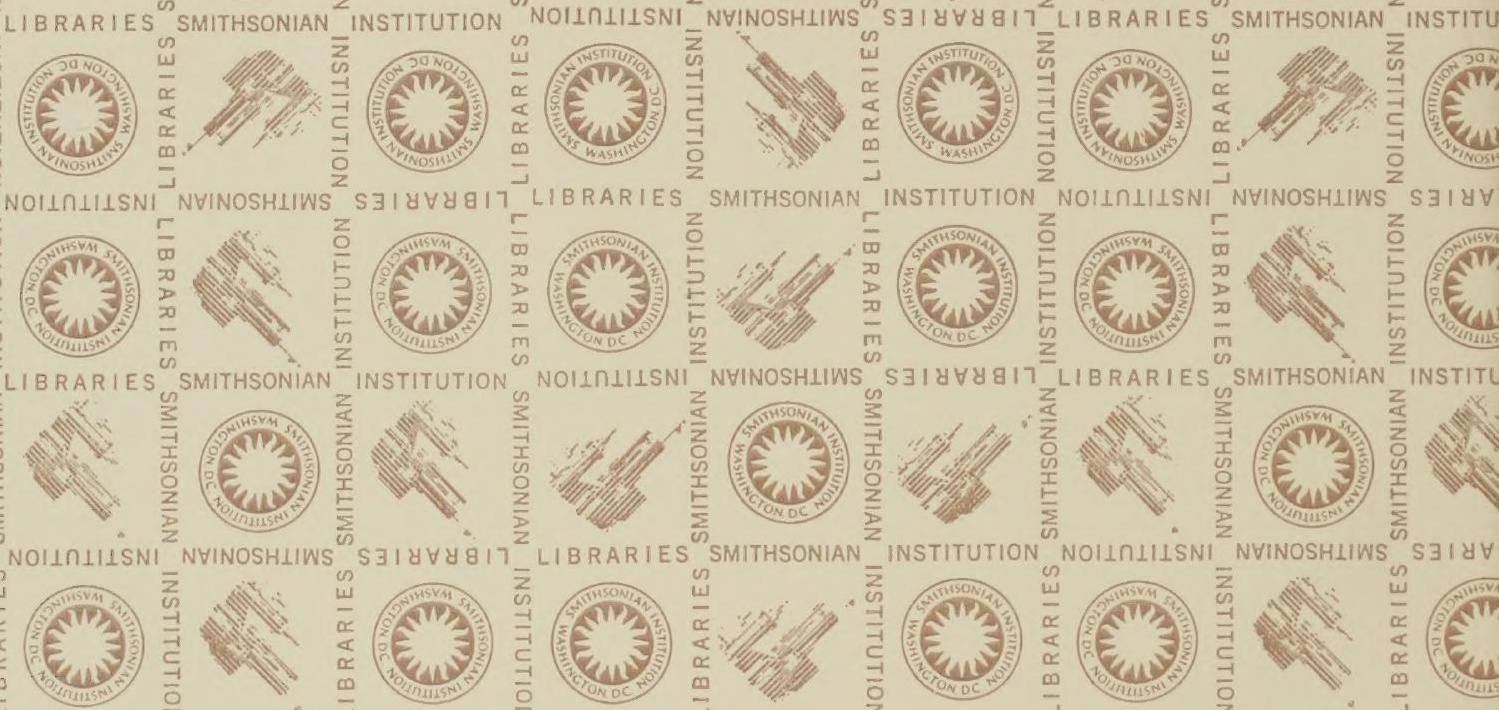

LI
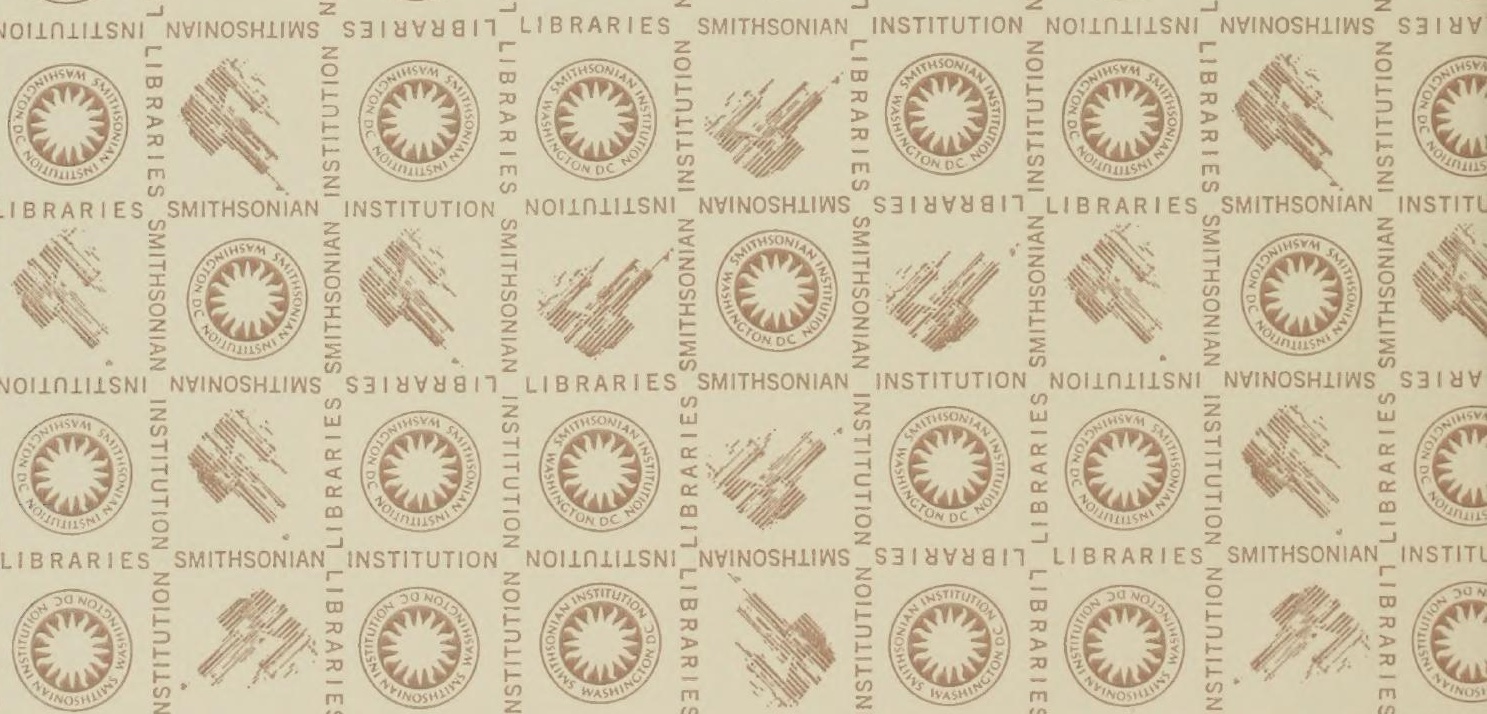

$\overbrace{}^{\mathrm{N}}$
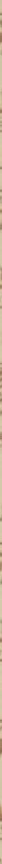

$S 314 \forall$
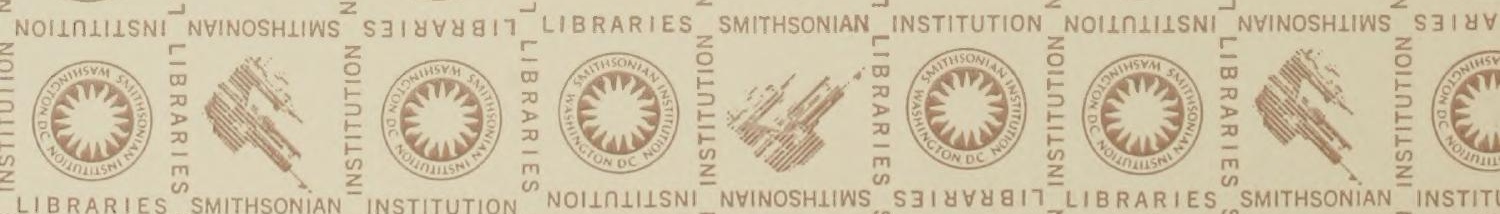

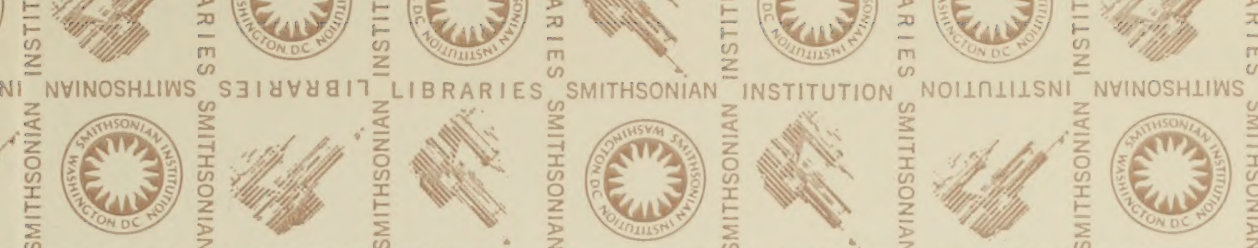

SMITHSONIAN
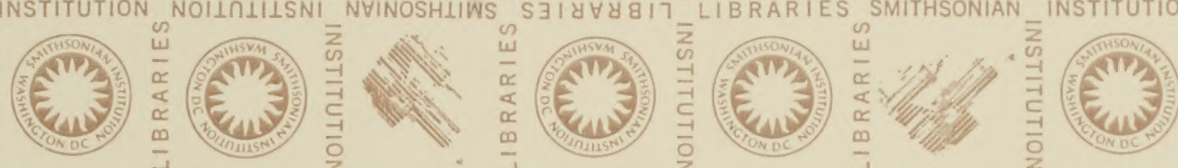

8

NHINOSHLINS
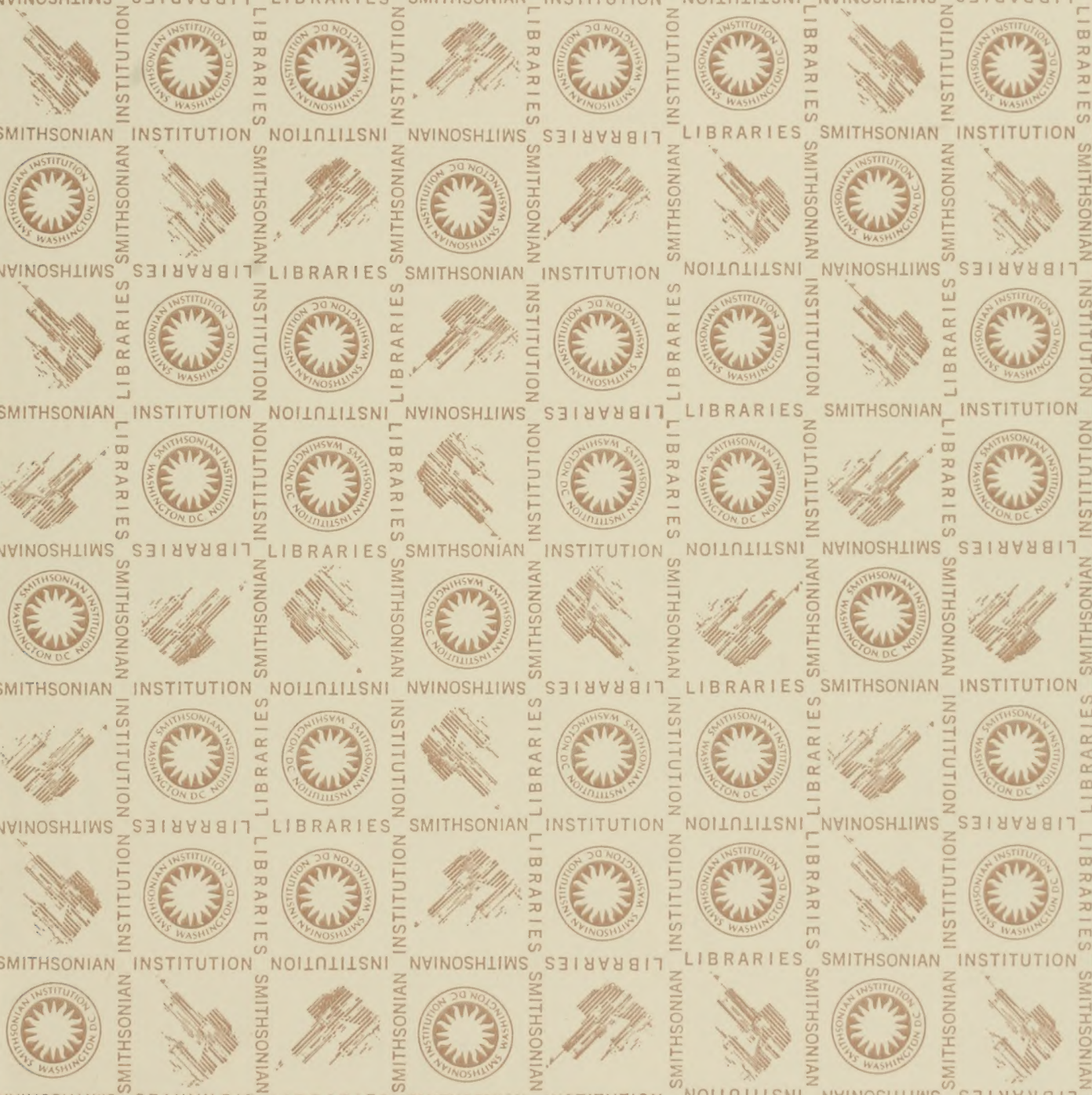

LIBRARIES
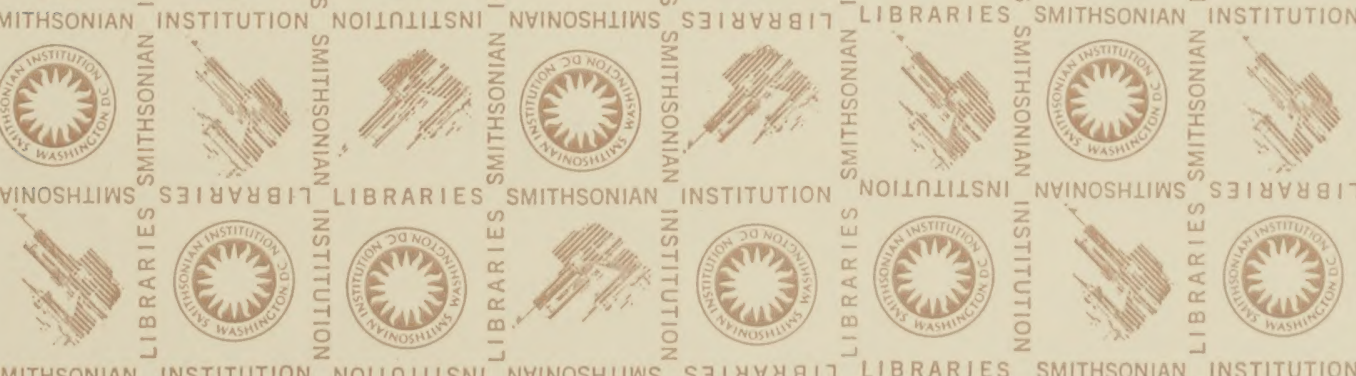

ES
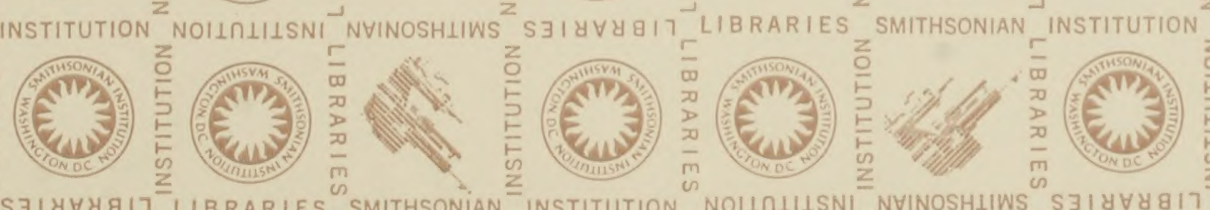


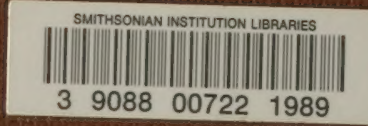

